Journal of Social Sciences (COES\&RJ-JSS)

ISSN (E): 2305-9249 ISSN (P): 2305-9494

Publisher: Centre of Excellence for Scientific \& Research Journalism, COES\&RJ LLC

Online Publication Date: $1^{\text {st }}$ April 2016

Online Issue: Volume 5, Number 2, April 2016

http://centreofexcellence.net/J/JSS/JSS\%20Mainpage.htm

\title{
Determinants of the Actual Use of E-Learning Systems: An Empirical Study on Zarqa University in Jordan
}

\author{
Dmaithan Abdelkarim Almajali ${ }^{1}$, Ra'ed (Moh'd Taisir) Masa'deh ${ }^{2}$, Prof. Musa Al-Lozi ${ }^{3}$ \\ 1. Assistant Professor, Management Information Systems Department, Faculty of \\ Economics and Administrative Sciences, Zarqa University, Zarqa, Jordan \\ 2. Associate Professor, Management Information Systems Department, School of \\ Business, The University of Jordan, P.O. Box 13876 Amman 11942 Jordan \\ ${ }^{3 .}$ Vice President for Humanities Faculties Affairs, the University of Jordan, Amman, \\ Jordan
}

\begin{abstract}
:
The study aimed to measure the impact of several antecedent factors (ease of use toward e-learning, usefulness toward e-learning, training on e-learning, and trust of e-learning) and intermediate factors (attitude to use e-learning and the intention to use e-learning) on the Jordanian Zarqa University students' actual use of e-learning systems. Measurement tool was developed to examine the relationship between the study variables. The sample of (340) was selected from Zarqa University students. Results indicated that ease of use toward e-learning, usefulness toward e-learning, training on e-learning, and trust of elearning impacted attitude to use e-learning. Also, ease of use toward e-learning, training on e-learning, and trust of e-learning did not impact the actual use of e-learning, while usefulness toward e-learning did. The study found that attitude to use e-learning mediate the relationship between the four antecedents and the students' actual use of e-learning systems; whereas the intention to use e-learning mediated the relationship between (ease of use toward e-learning, usefulness toward e-learning, training on e-learning) and the students' actual use of e-learning systems, while trust of e-learning did not.
\end{abstract}

Keywords:

E-learning, Actual Use of E-Learning Systems, Jordan

\section{Citation:}

Almajali, Dmaithan Abdrlkarim; Masa'deh, Ra'ed (Moh'd Taisir); Al-Lozi, Prof. Musa (2016); Determinants of the Actual Use of E-Learning Systems: An Empirical Study on Zarqa University in Jordan; Journal of Social Sciences (COES\&RJ-JSS), Vol.5, No.2, pp: 172-200. 


\section{العوامل المحددة للإستخدام الفعلي لأنظمة التعلم الاككتروني: دراسة ميدانية على جامعة الزرقاء في الاردن الأنظم}

د. دميثان عبدالكريم المجالي 1'، د. ر رائد (محمد تيسير) مساعده 2، أ.د. موسى اللوزي 3

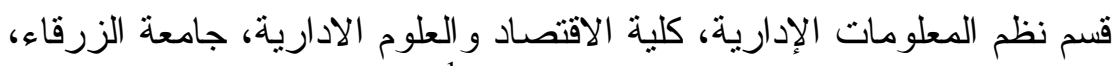

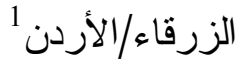

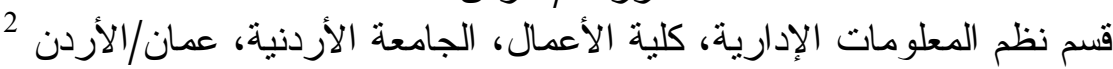
نائب رئيس الجامعة الاردنية لثؤون الكليات الانسانية، الجامعة الأردنية، عمان/الأردن، الأردن،

\section{ملخص الدراسة}

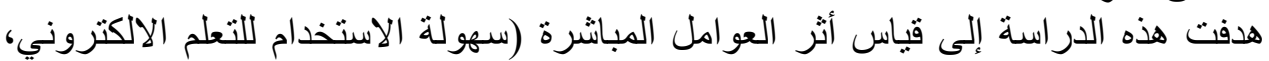

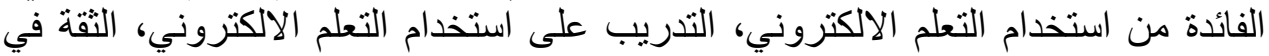

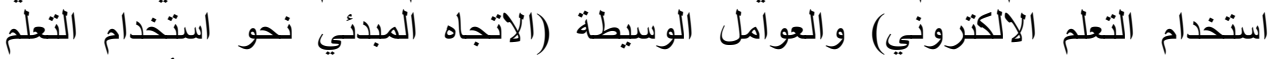

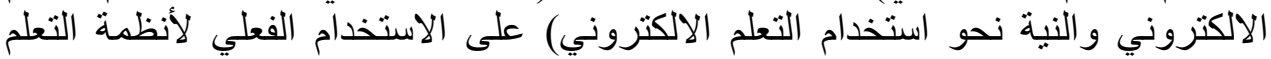

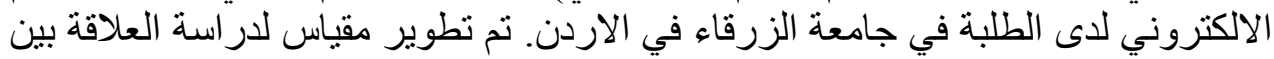

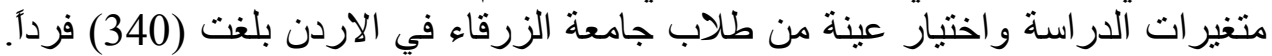

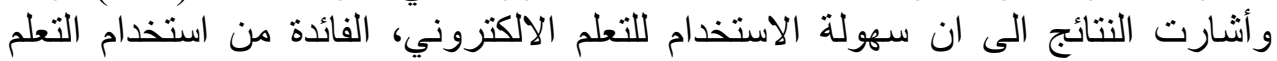

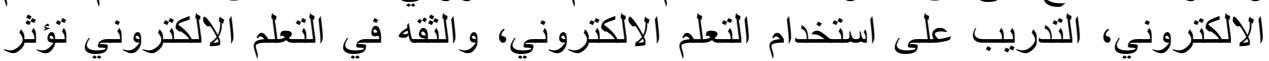

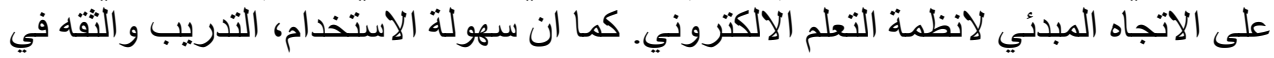

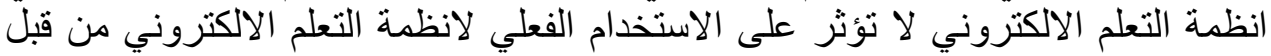

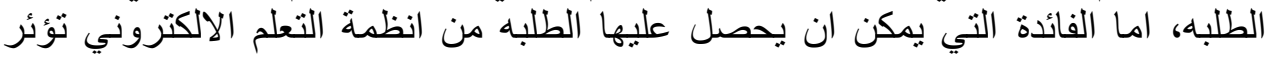

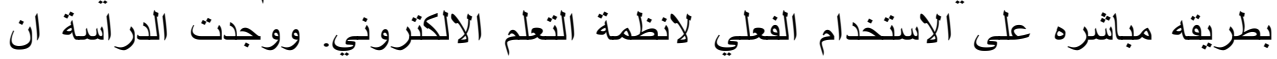

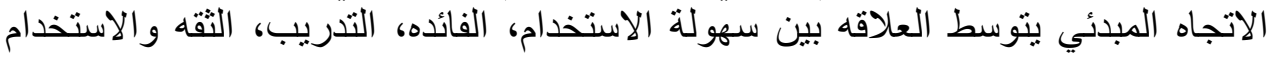

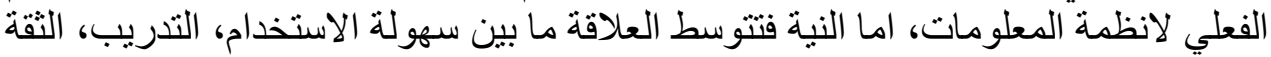

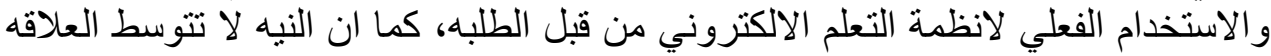
بين الفائده و الاستخدام الفعلي لانظمة التعلم الالكتروني.

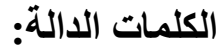
التعلم الالكتروني ، أنظمة التعلم الالكتروني ، الجامعات الأردنية

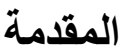

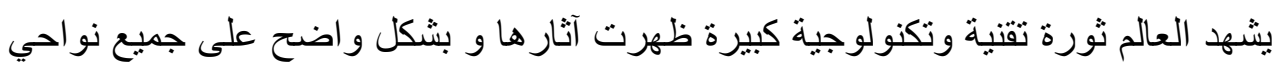

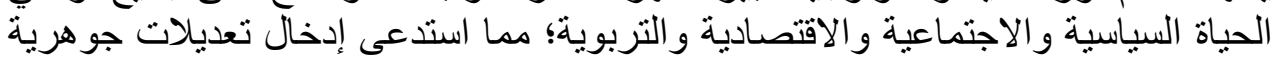

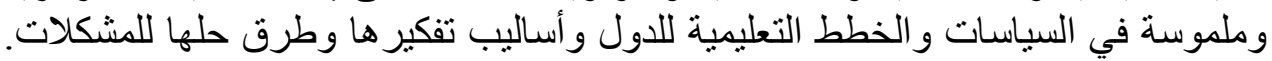

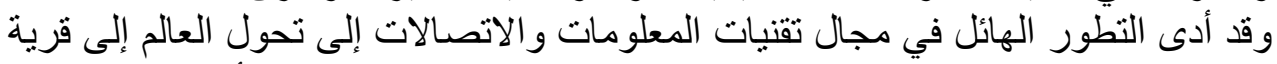

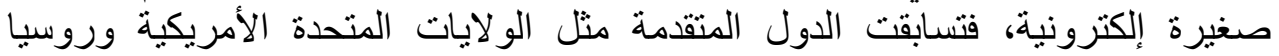

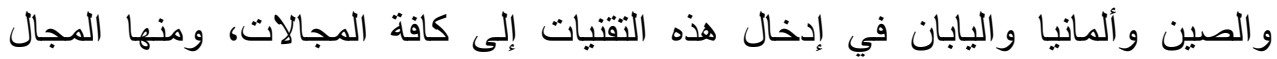
التعليمي. وقد ساعد التطور التقني وتكنولوجيا لإنيا الاتصالات الحديثة في التفكير بجدية بإعادة التهات 
النظر في تثكيل المؤسسات التعليمية من خلال توفير بيئات وطرق جديدة للتعليم، مما مهر لظهور نمط جديد من أنماط التعلم وهو التعلم الالكتروني.

وتعد تقنية المعلومات الإلكترونية وما يرافقها من وسائط متعددة من أنجح الوسائط لتوفير البيئة

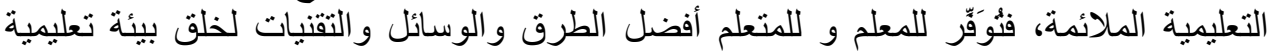

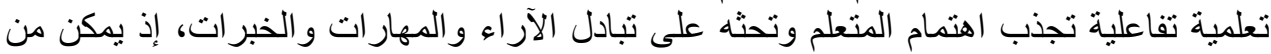

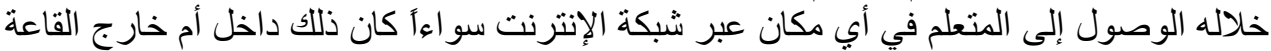

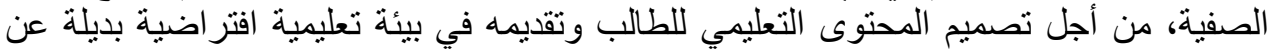

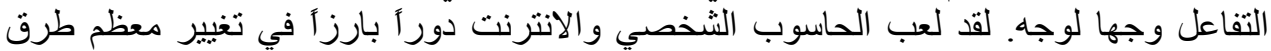

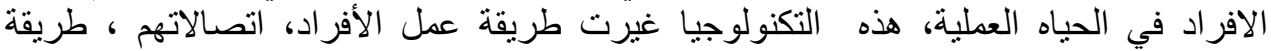

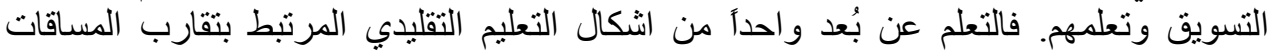

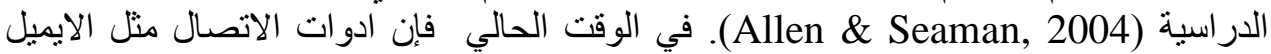

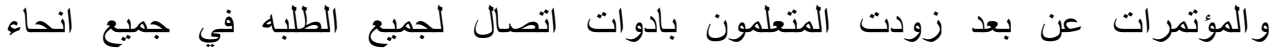
العالم (Theriot, 2004; Masa'deh et al., 2013).

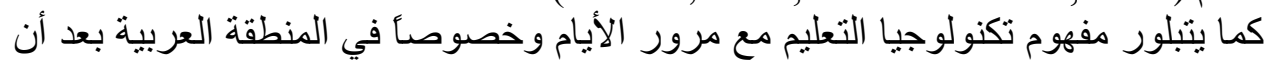

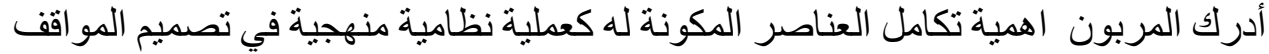

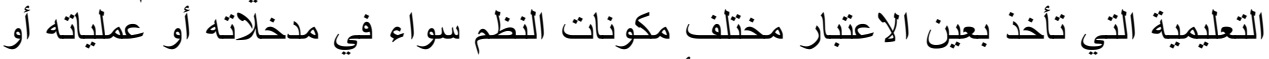

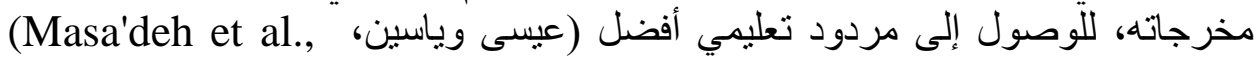

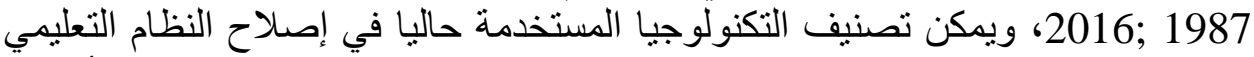

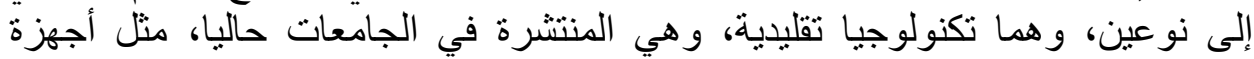

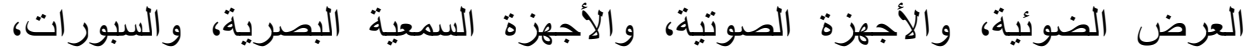

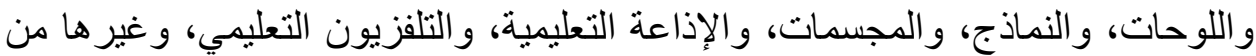

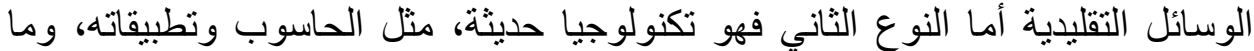

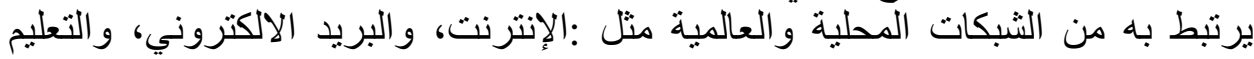
الافتر اضي (الجملان، 2004).

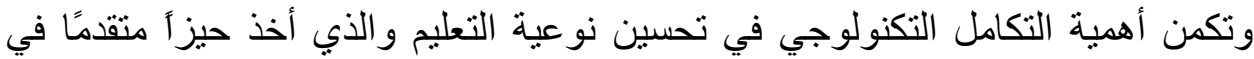

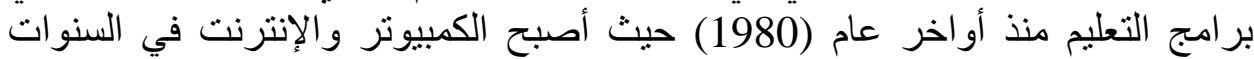

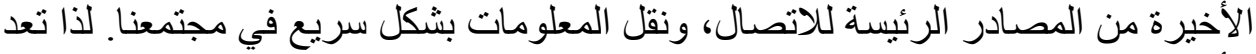

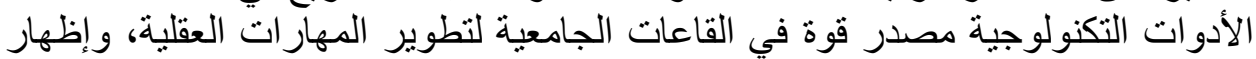

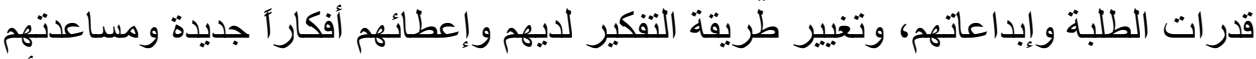

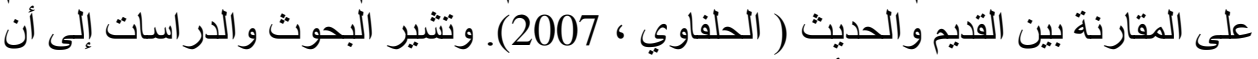

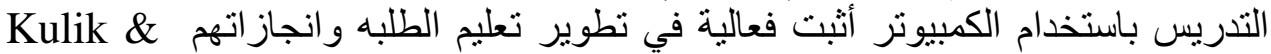
(Kulik, 1991; Diana, 1992) التكنولوجيا في إظهار طفرة أو تغيير في عملية التعلم والتعليم، وإكساب الطلبة خلئ خبرة تعليمية.

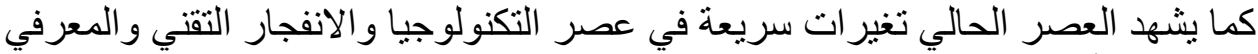
و الثقافي، فأصبحت الحاجة ملحة إلى استر اتيجيات جديدة توجه مسار التعليم في العصر الأفر التئر 
الحديث لمواكبة التقدم العلمي و التكنولوجي، وسر عة التغير التي يشهدها العالم المعاصر

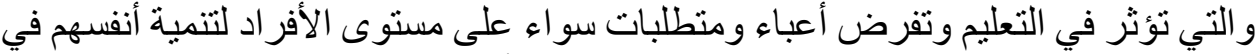

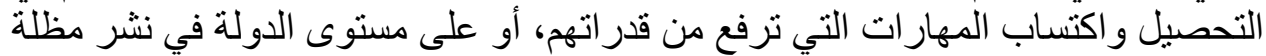

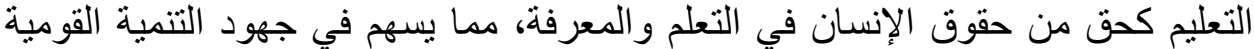

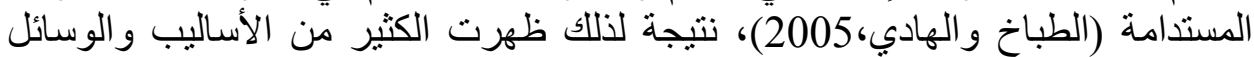

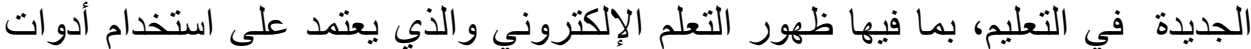

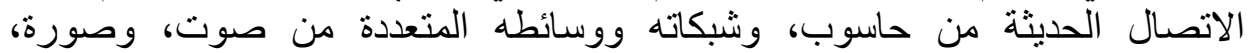

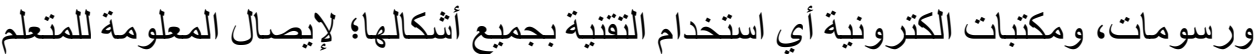

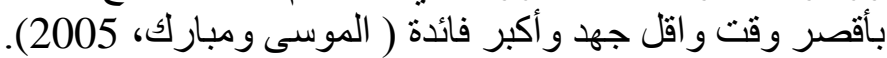

وقد أورد عبد العزيز (2008) عدداً من المميزات التي تميز التعلم الإلكتروني عن غيره

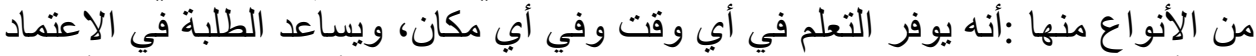

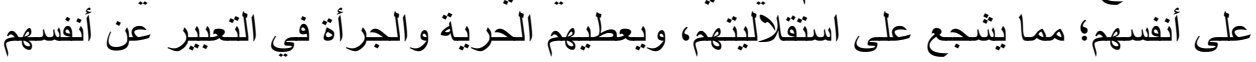

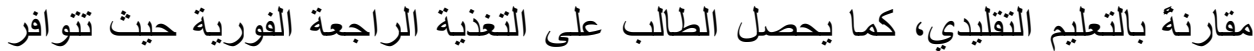

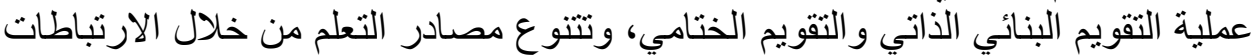

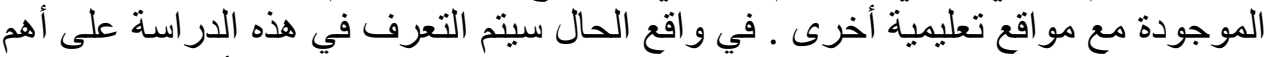

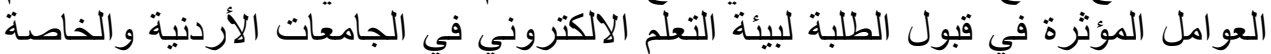
والاطلاع على أهم الحلول التي من شانها أن تخفف من عدم إقبال الطلبة لبيئة التعلم الالكتروني.

مشكلة الدراسة تعد التكنولوجيا اليوم من أكثر عناصر التدريس أهمية في المؤسسات التعليمية في مختلف

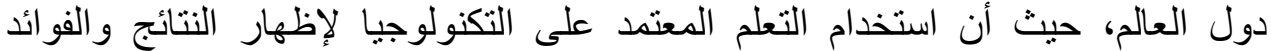

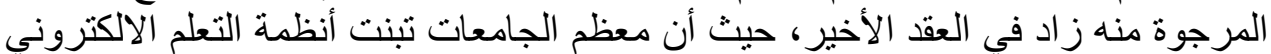

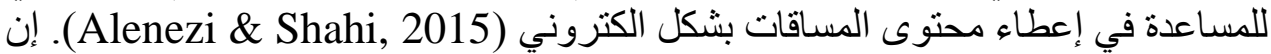

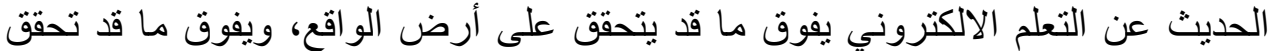

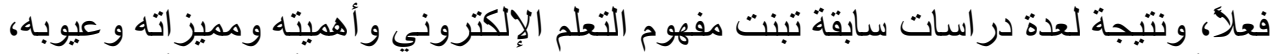

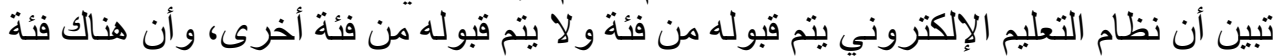

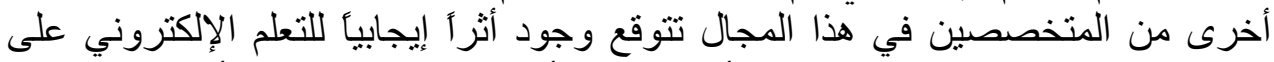

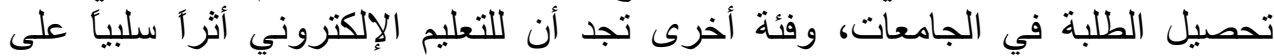

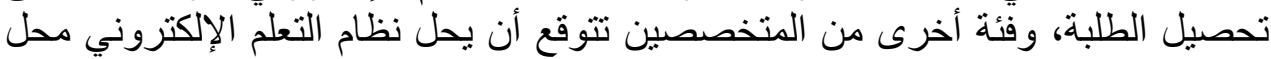
التعليم النظامي، مع ضرورة التكامل بين كل من التعليم النظامي والتعليم الإلكتروني

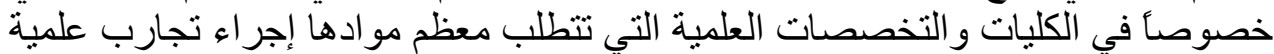

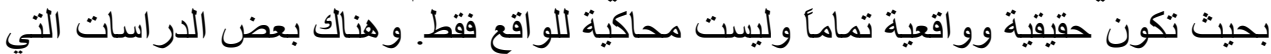

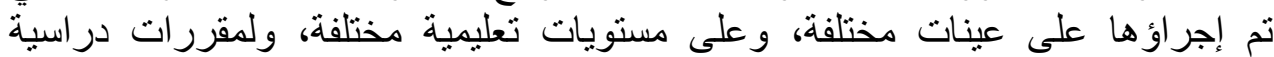
مختلفة، أثبتت فاعلية نظام التعلم الإلكتروني كطريقة تعليمية وأنه سيكون له أثر إيجابي في

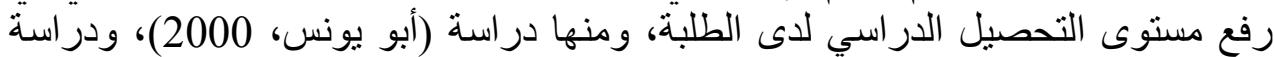


كما أن معظم الدراسات التطبيقية اهتمت في التعلم الالكتروني ولكن القليل من هذه الته

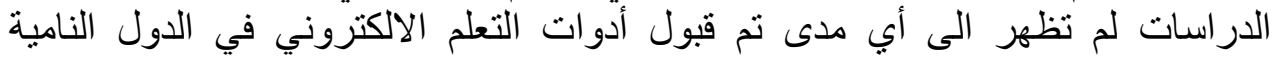

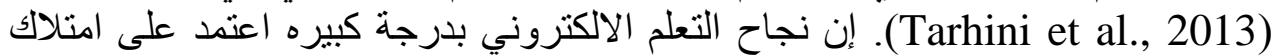

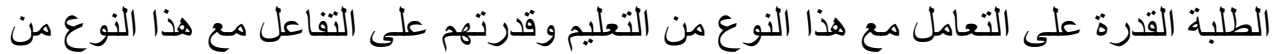

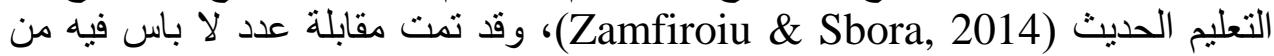

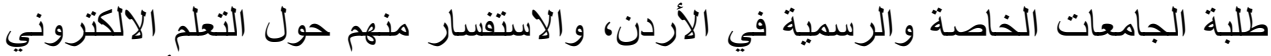

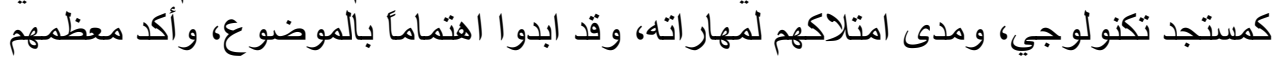

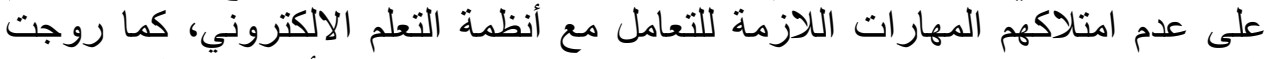

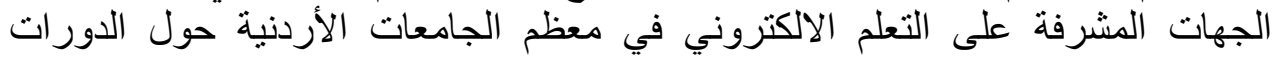

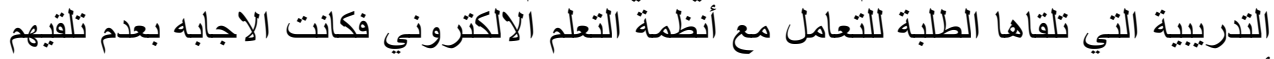

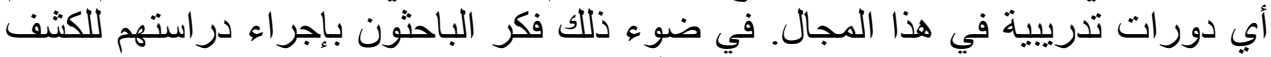

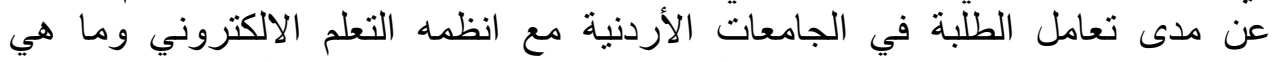

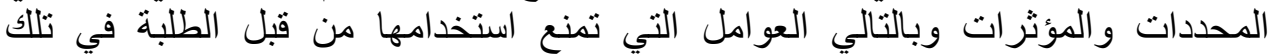

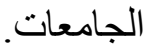

\section{أهمية الدراسة أهنة}

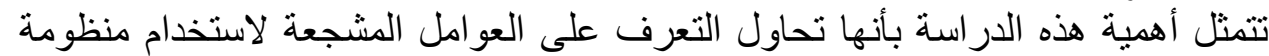

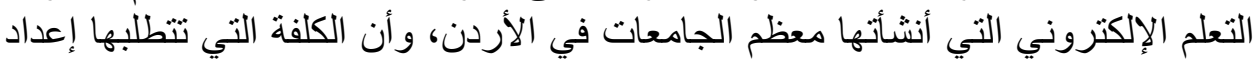

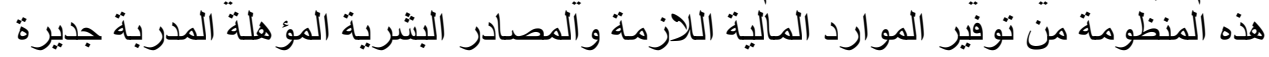

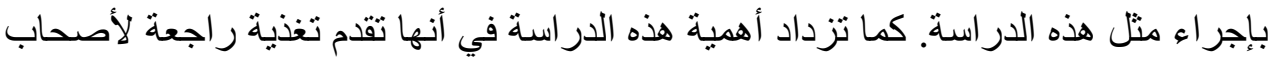

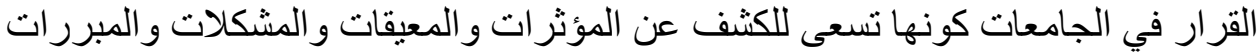

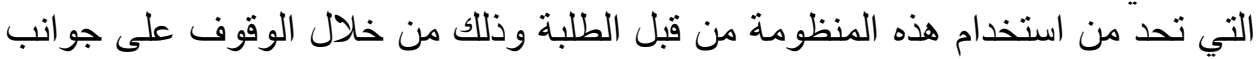

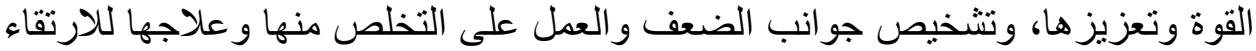

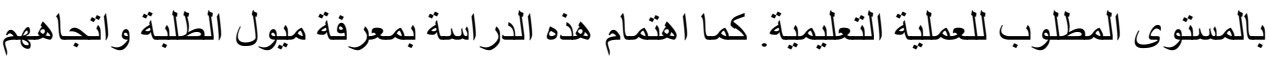

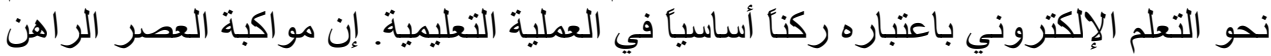

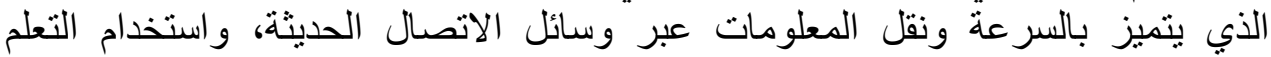

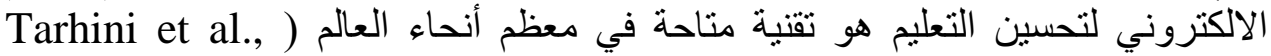

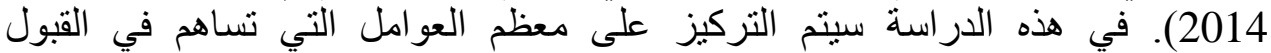

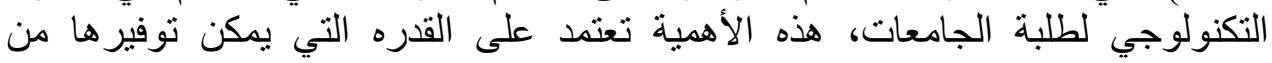

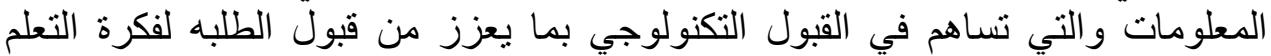

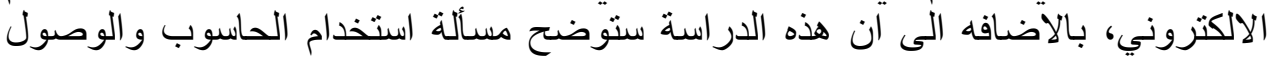

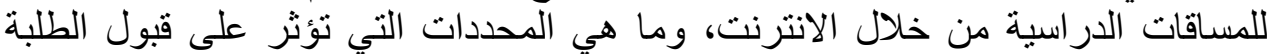

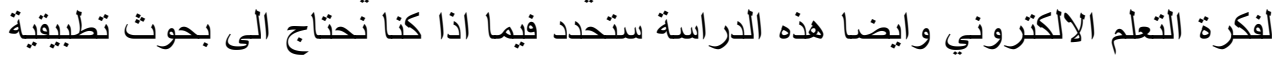
لمعرفة الفجوة التكنولوجية للطلبه و التي يمكن ان تؤثر على استخدام التعلم الالكتروني. 


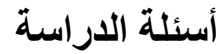
1- ما أثر العو امل المباثرة (سهولة الاستخدام للتعلم الالكتروني، الفائدة من استخدام التعلم

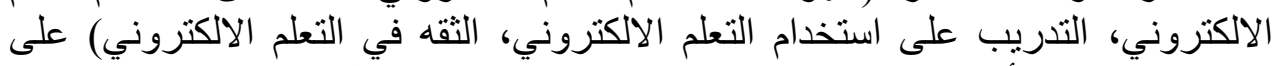

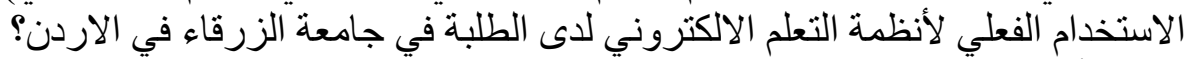

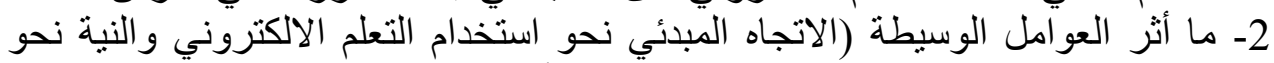
استخدام التعلم الالكتروني) على الاستخدام الفعلي لأنظمة التعلم الالكتروني لألى الألى الطلبة في

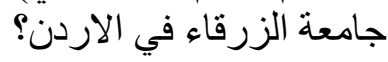
أهداف الدراسة الدة: 1- تحديد العوامل المبانرة (سهولة الاستخدام للتعلم الالكتروني، الفائدة من استخدام التعلم

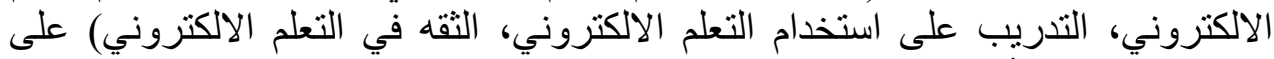

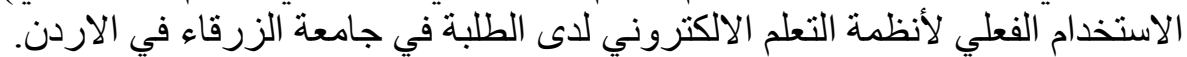

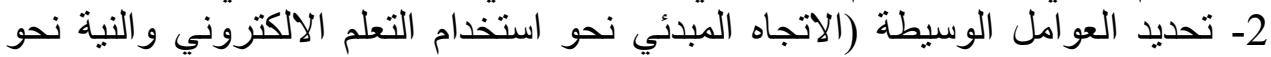

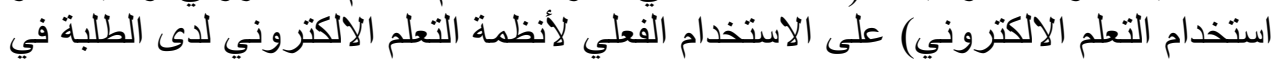

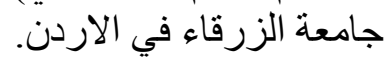

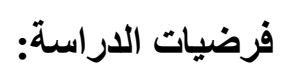

H1- يو جد علاقة ذات دلالة احصائية بين سهولة الاستخدام و الاتجاه المبدئي نحو استخدام

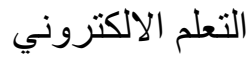

-H2 يوجد علاقة ذات دلالة احصائية بين الفائده من استخدام التعلم الالكتروني و الاتجاه المبدئي نحو استخدام التعلم الالكتروني

H3 يوجد علاقة ذات دلالة احصائية بين التدريب والاتجاه المبدئي نحو استخدام التعلم الالكتروني

H4 يوجد علاقة ذات دلالة احصائية بين الثقه في التعلم الالكتروني و الاتجاه المبدئي نحو استخدام التعلم الالكتروني

-H5 يوجد علاقة ذات دلالة احصائية بين الاتجاه المبدئي نحو استخدام التعلم الالكتروني التئي و النيه نحو استخدام التعلم الالكتروني

H6- يوجد علاقة ذات دلالة احصائية بين النيه نحو استخدام التعلم الالكتروني و الاستخدام الفعلي للتعلم الالكتروني

H7 يوجد علاقة ذات دلالة احصائية بين سهولة الاستخدام و الاستخدام الفعلي للتعلم الالكتروني 
-H8 يوجد علاقة ذات دلالة احصائية بين الفائده من استخدام التعلم الالكتروني و الاستخدام الفعلي للتعلم الالتروني

-H9 يوجد علاقة ذات دلالة احصائية بين التدريب والاستخدام الفعلي للتعلم الاكتروني -H10 يوجد علاقة ذات دلالة احصائية بين التقه في التعلم الالكتروني والاستخدام الفعلي للتعلم الالكثروني

H11 يتوسط الاتجاه المبئي العلاقة ما بين سهولة الاستخدام و الاستخدام الفعلي للتعلم الالكتروني

-H12 يتوسط الاتجاه المبدئي العلاقة ما بين الفائده من استخدام التعلم الالكتروني و الاستخدام الفعلي للتعلم الالكتروني

-H13 يتوسط الاتجاه المبدئي العلاقة ما بين التدريب والاستخدام الفعلي للتعلم الالكتروني -H14 يتوسط الاتجاه المبدئي العلاقة ما بين الثقه في التعلم الالكتروني و الاستخدام الفعلي للتعلم الالكتروني

H15 يتوسط النيه نحو استخدام التعلم الالكتروني العلاقة ما بين سهولة الاستخدام و الاستخدام الفعلي للتعلم الالكتروني

يتوسط النيه نحو استخدام التعلم الالكتروني العلاقة ما بين الفائده من استخدام التعلم

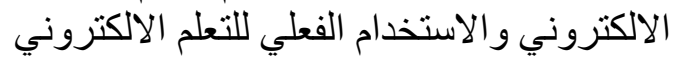

-H17 الفعلي للتعلم الالكتروني ئتوسط النيه نحو استخدام التعلم الالكتروني العلاقة ما بين التقه في التعلم الالكتروني و الاستخدام الفعلي للتعلم الالكتروني.

$$
\text { أدبيات الدراسة }
$$

عند مر اجعة أدبيات الدراسة ذات العلاقة بالدر اسة الحالية، لاحظ الباحثّن ندرة الدر اسات

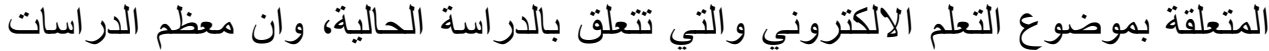

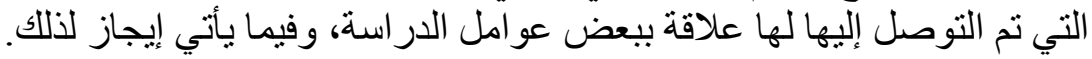

استطلع الباحثنان في دراسة ميكلسون وسميث (1999) آراء بعض الطلبة حول مزايا

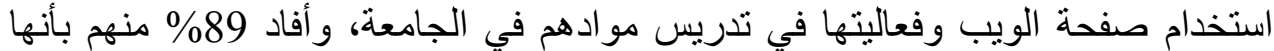

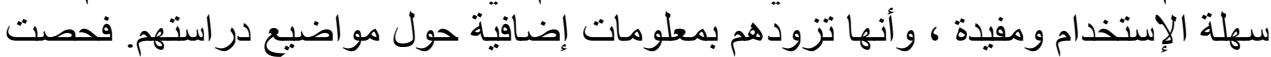
در اسة تيري ونيفجي (2000) اتجاهات طلبة جامعة فنلندية بخصوص حود در استهم في جامعة 


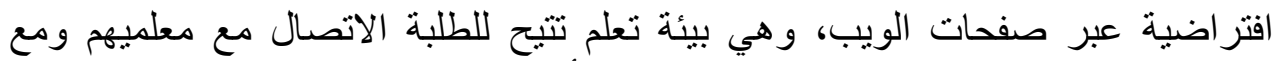

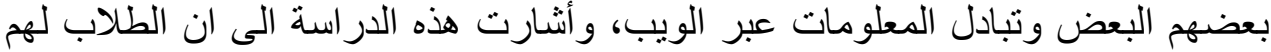
حاجات متعددة وفريدة ويجب مر اعاتها عند تطبيق هذا النظام. توصلت دراست استة البعلوجي وني

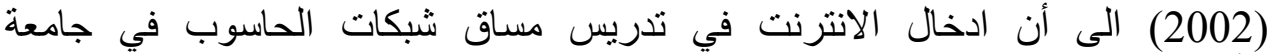

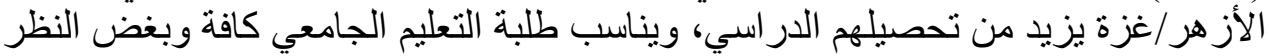

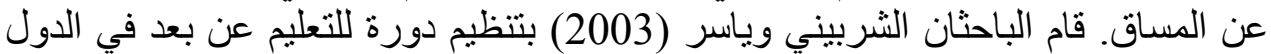

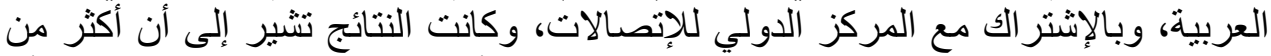

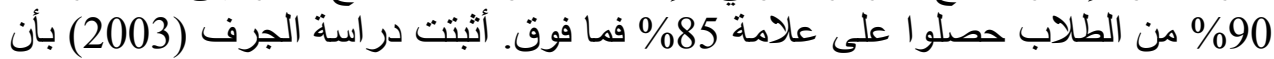

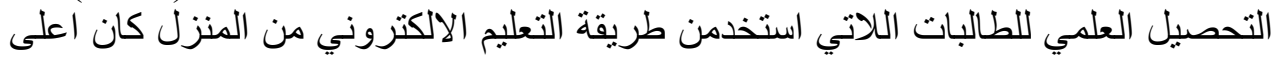

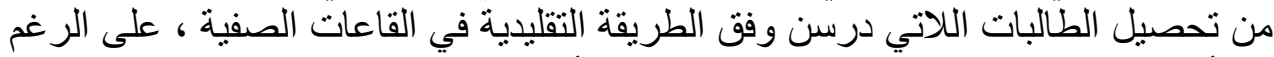

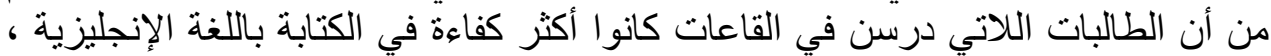
أي أن استخدام الأسلوب الإلكتروني ساهم في تحسين مستوى الطالبات في اللغة الإنجليزية الإنية.

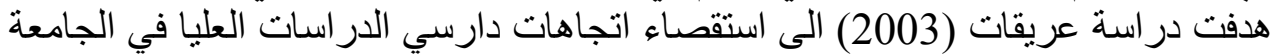

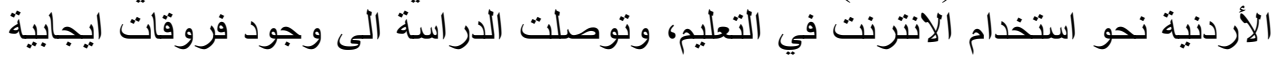

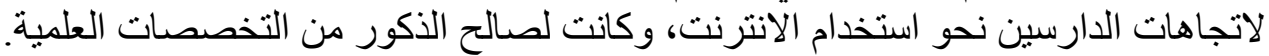

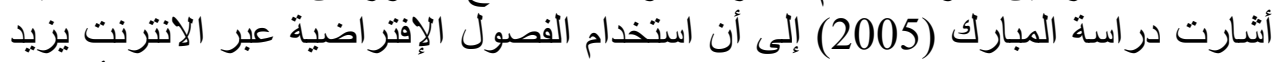

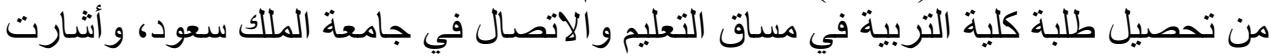

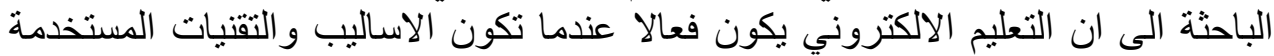

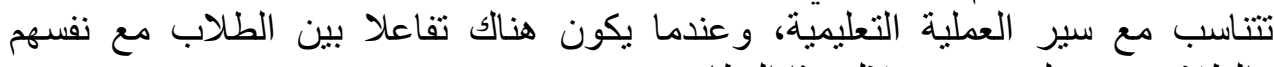
و الطلاب مع معلمبهم من خلابل هذا النظام.

كما هدفت دراسة كوهانج (2004) الى استقصاء اتجاهات الدارسين نحو التعلم

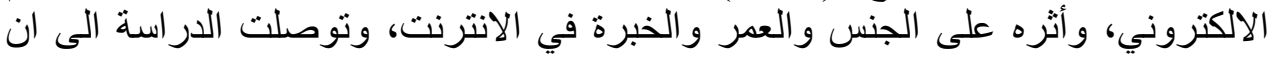

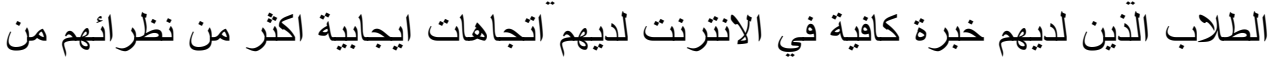

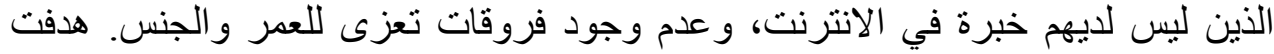

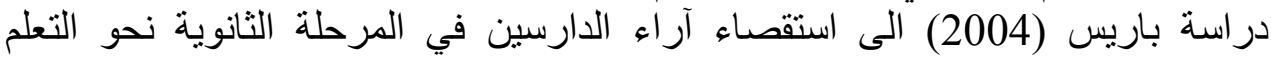

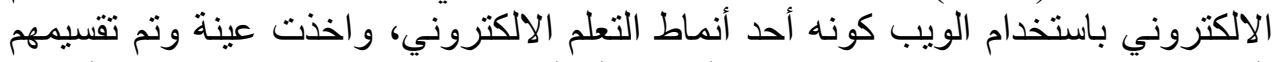
الى قسم تجريبي (درس مساق تكنولوجيا المعلومات والاتصالات باتئ باستخدام الويب)

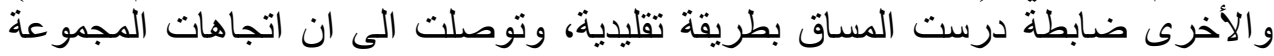

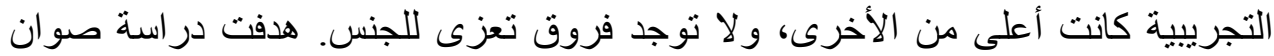

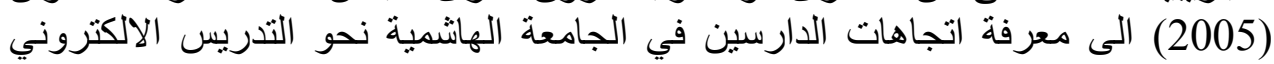

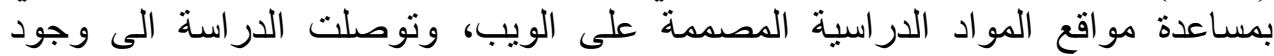

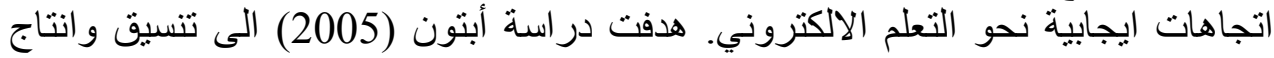

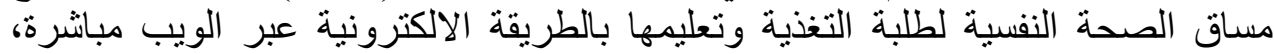

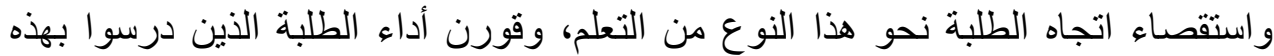

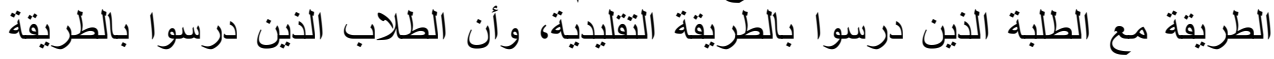

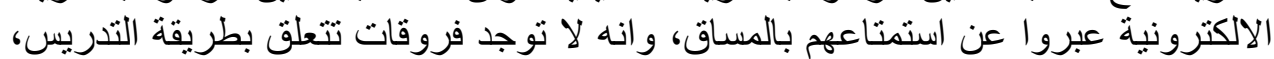

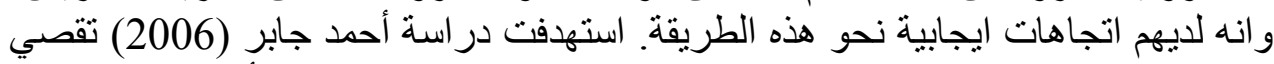
فعالية نظام التعلم الالكتروني لاى طلبة كلية التربية في سوهاج، وقياس أثره على المفاهيم 
الأساسية الخاصة بالمقرر ات الدراسية، وتوصلت الى ان البرنامج فعال وساهم في تحصيل

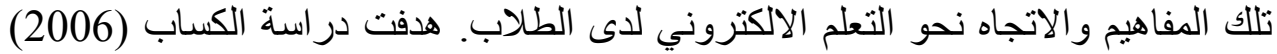

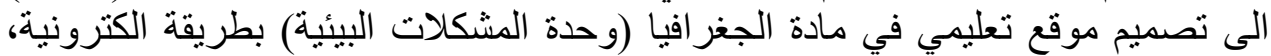

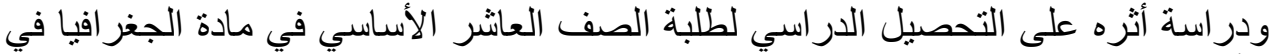

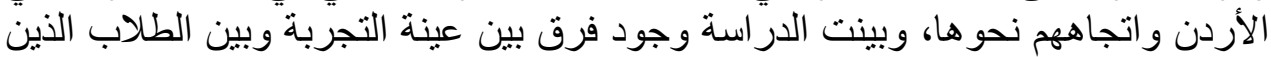

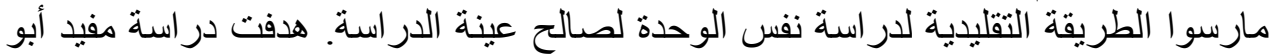

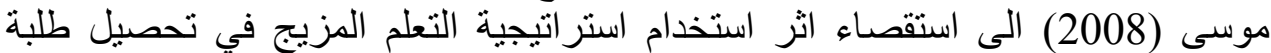

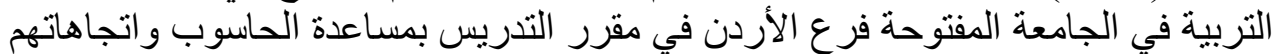

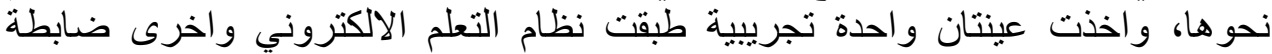

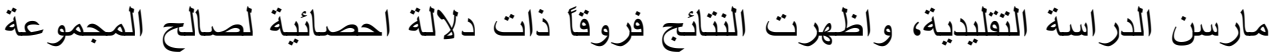

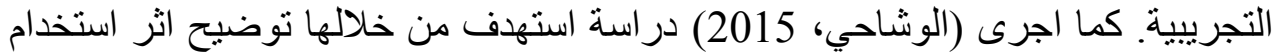

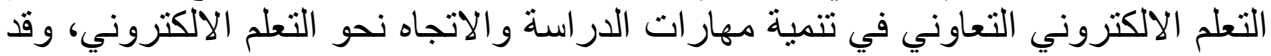

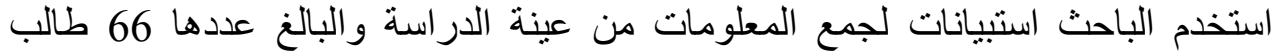

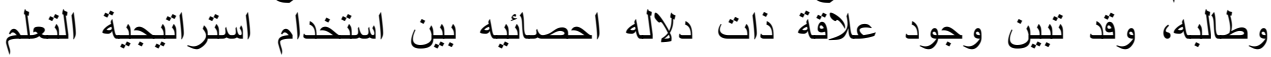

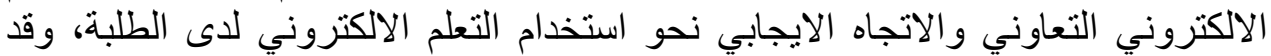

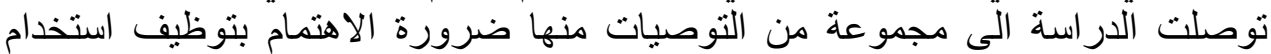

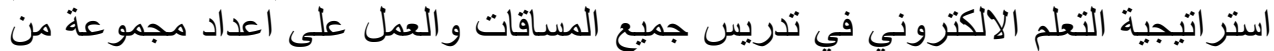
قو ائم التعلم الالكتروني في جميع المساقات الدر اسية.

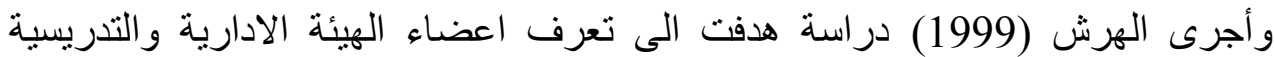

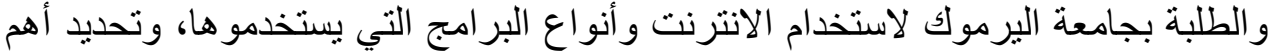

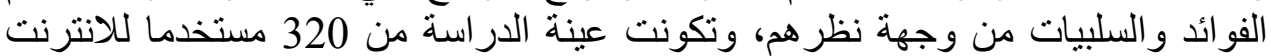

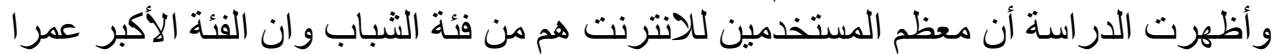

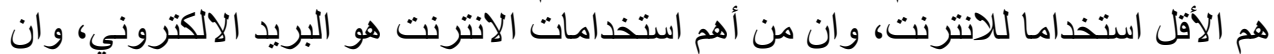

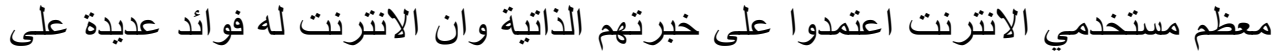

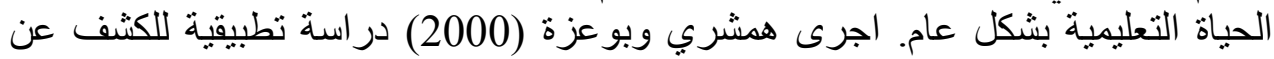

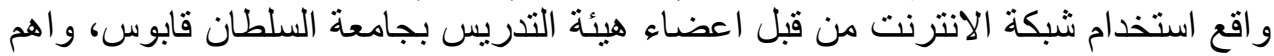

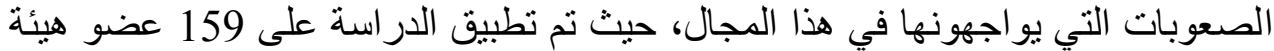

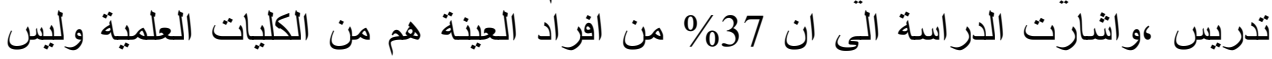

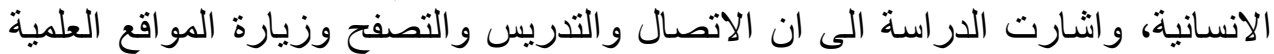

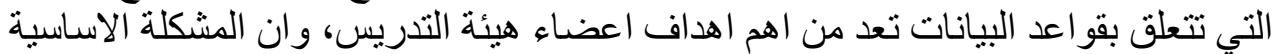

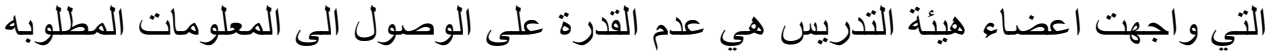

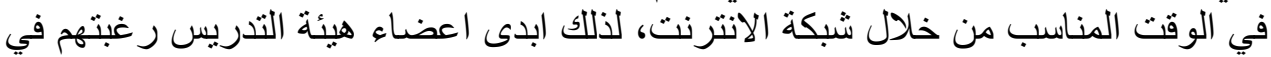

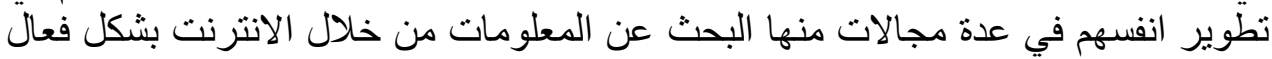

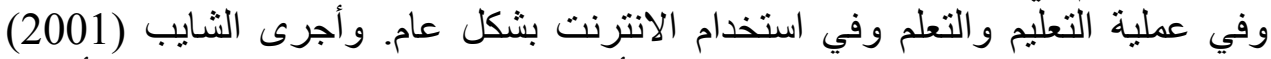

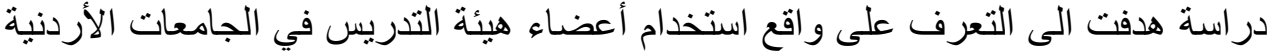

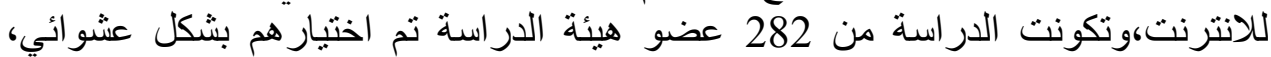

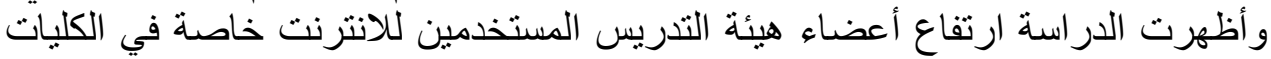




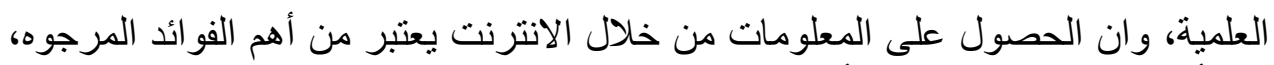
كما أثنارت الدراسة الى ان أفراد العينة لديهم اتجاهات ايجابية نحو استخدام الانترنت التهن.

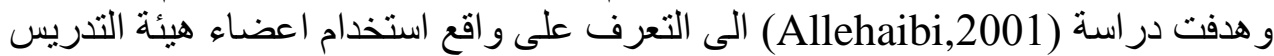

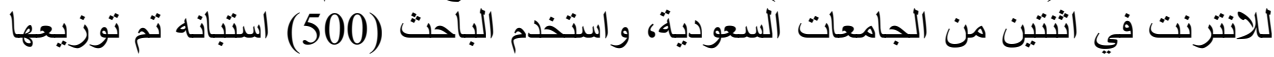

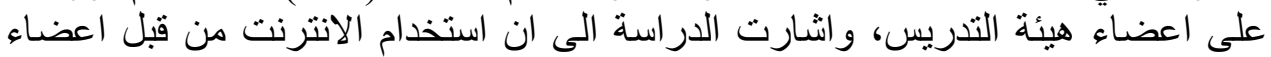

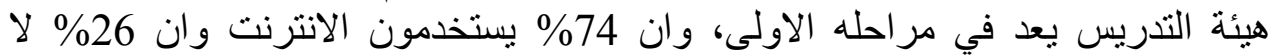

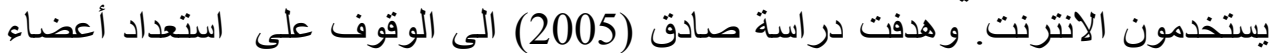
الهيئة التدريسية بجامعة جنوب الوادي بمصر لتطوير التعلم الالكتروني واستخدامه، وقد

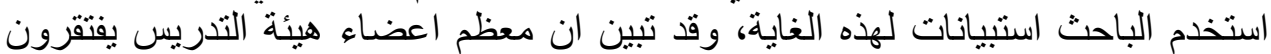

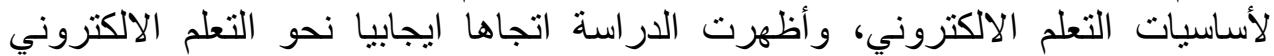

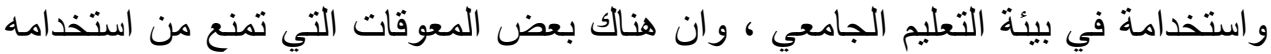

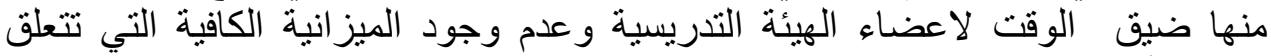
بتدريب أعضاء هيئة التدريس على التعلم الالكتروني.

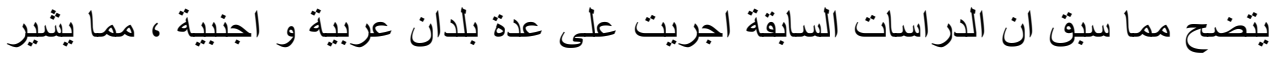

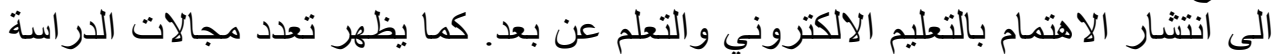
عبر الويب (اكثر من مساق تعليمي) مما يؤكد امكانية تطبيق التعليم الالكتروني على فئ كافة

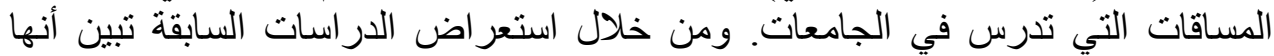
ركزت على الموضو عات التالية :

•هناك العديد من الدراسات التي أكدت على الدور الإيجابي للتعليم الإلكتروني على التى الته

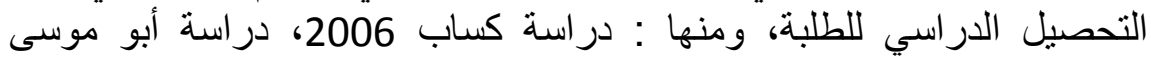

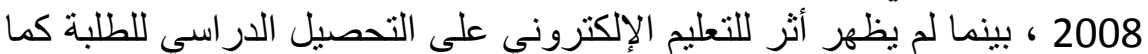

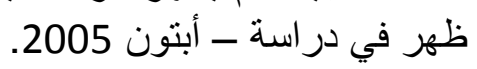
•هناك دراسات لم تظهر اتجاهات ايجابية نحو التعلم الإلكتروني تعزى للفئة العمرية،

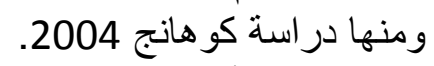

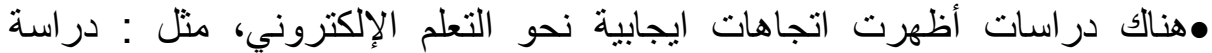

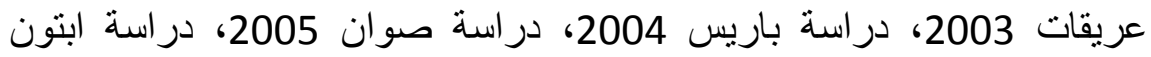
2005، در اسة كساب 2006، 2003، ودراسة أبو موسى دابس 2008.

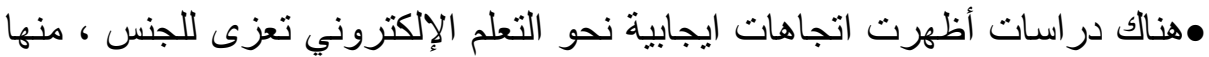

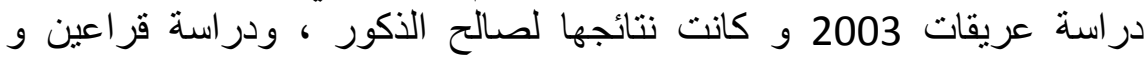
القضاة و كانت نتائجها لصالح الإناث. •و هنالك دراسات أظهرت اتجاهات ايجابية نحو التعلم الالكتروني تعزى للخبرة في الاني

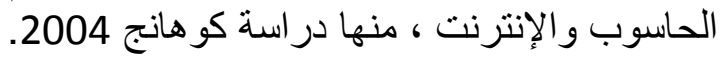
•و هناك در اسات أظهرت أن للتخصص العلمي أثر دالا إحصائياً لصالح التخصصات

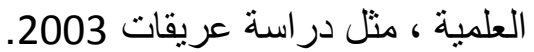

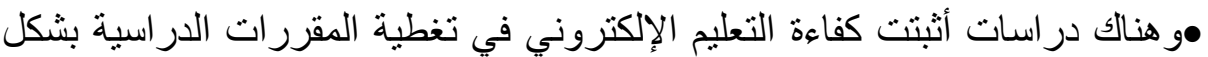

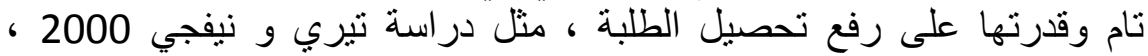


ودراسة الثربيني و ياسر 2003، ودراسة الجرف 2003 ، ودراسة المبارك 2005 ، و در اسة البعلوجي 2002.

•و هنالك دراسات أثتتت سهولة استخدام نظام التعلم الالكتروني والمودل مثل دراسة

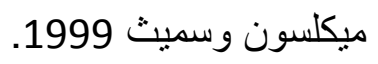

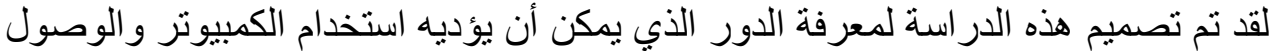

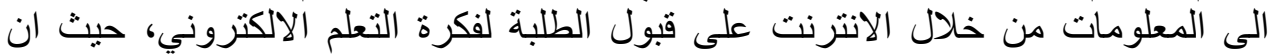

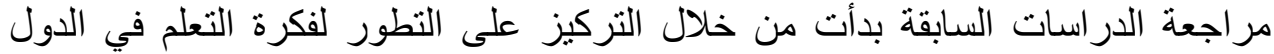

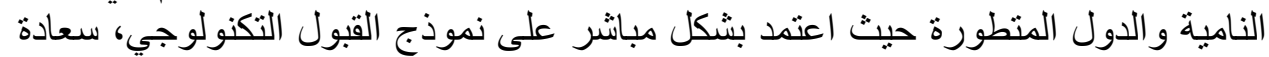

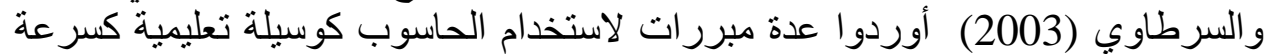

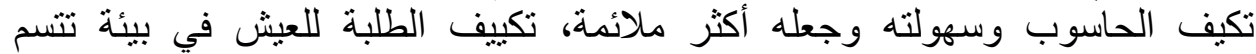

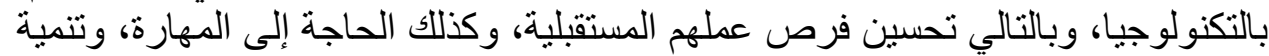

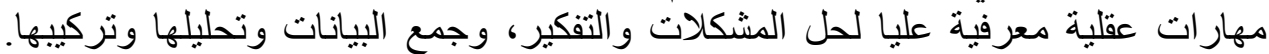

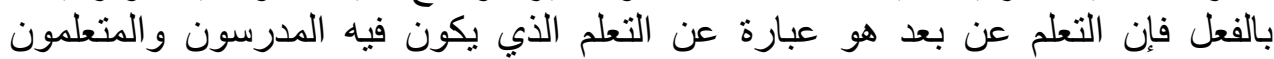

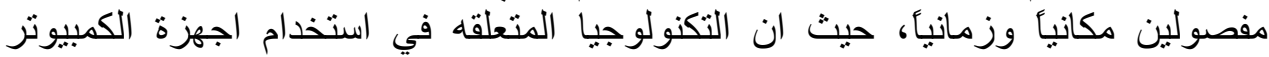

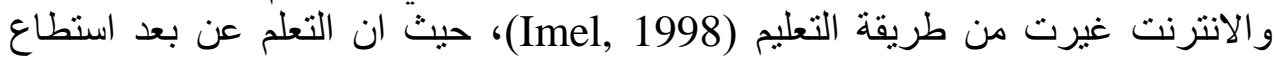

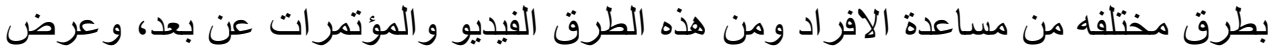

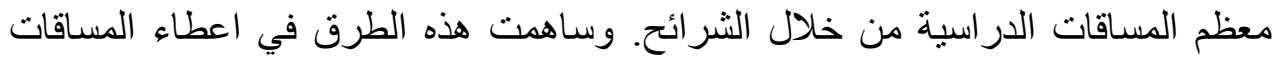

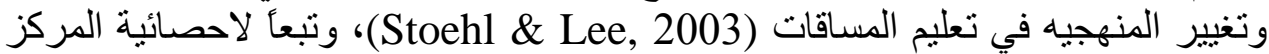

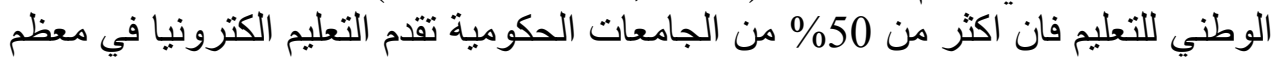

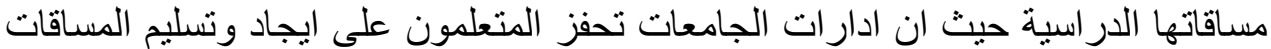

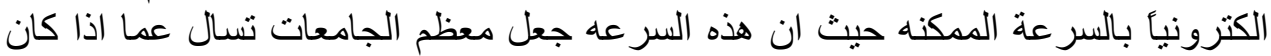

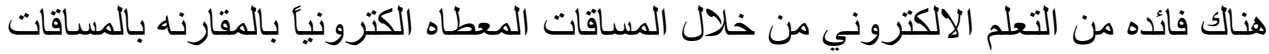

المعطاه تقليدياً ام لا. لان.

كما أن التدريب يزيد من قدرة الافراد على استخدام تطبيقات انظمة المعلومات

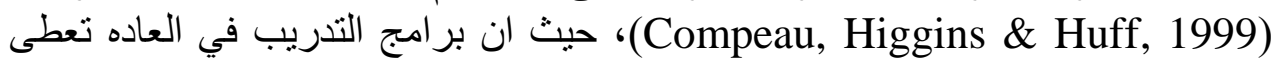

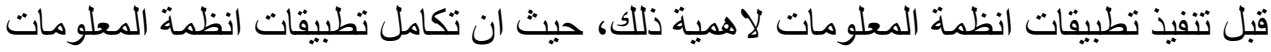

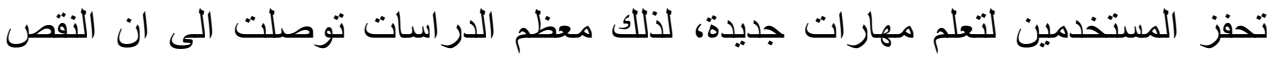

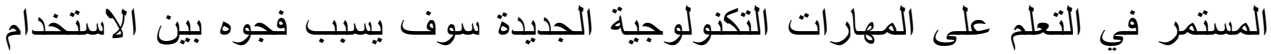

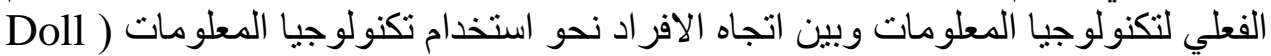
et al., 2003

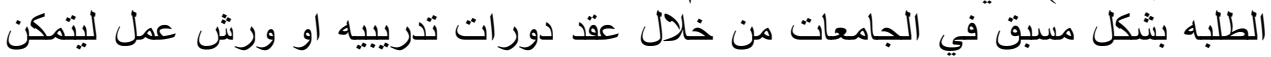

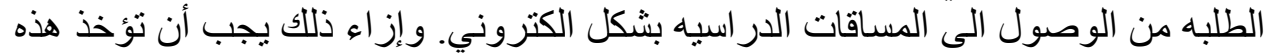

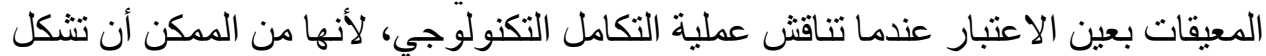

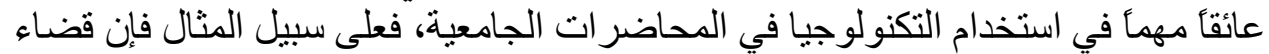

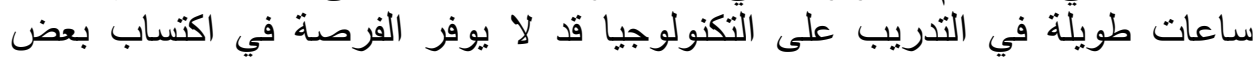

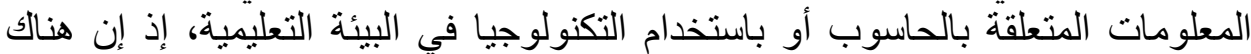
عوامل أخرى مثل الدعم التقني، والدعم الحكومي، والميز انية الكافية، المعدات الكافية من النية النية 


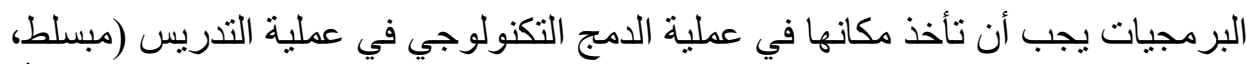

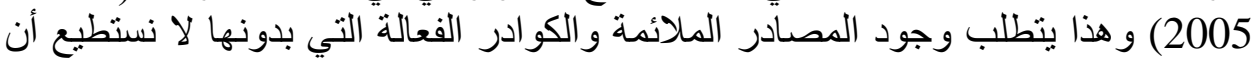

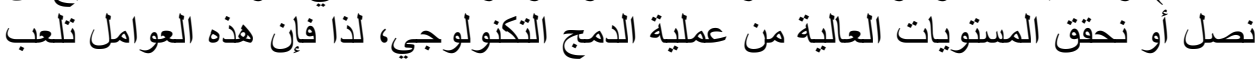

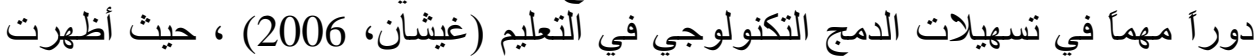
الدراسات إن إدخال التكنولوجيا في العملية التعليمية عملية صعبة. فئه ويشير (2000) (George

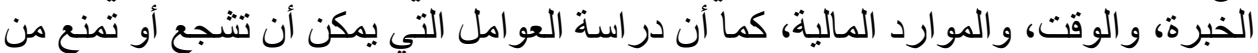

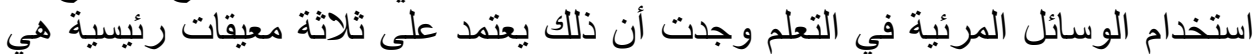

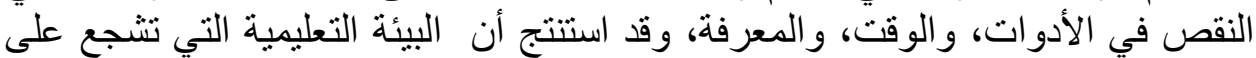
استخدام الَّسائل المرئية في التعلم سيكون لها ظهور أكثر إذا ما توفرت التهات المتطلبات الآتية المعدات اللازمة، الوقت الكافي لتطوير المواد، الدعم التقني، وسهولة لونة استخدام البرمجيات.

كما أن الجانب المهم الآخر في عملية الدمج التكنولوجي هو القلق من استخدام التكنولوجيا، إذ منذ دخول الحاسوب في البيئة التعليمية أصبح لدى الدئ المدرسين قلق من الطريقة التي سوف

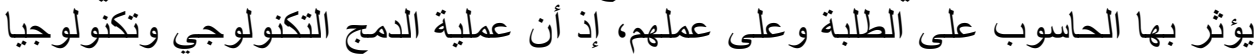

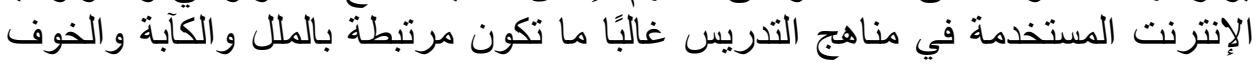
مجهول السبب، و المستوى العالي من القلق، حيث إن التكنولوجيا المثيرة للقلق مرتبطة فئنة بالتجربة غير السهلة، أو من الضخوط في استخدام التكنولوجيا التي يساء فهمها على أنها

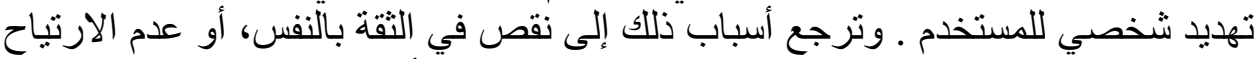
وبعض حالات الخوف من استخدام الحاسوب و التكنولوجيا الأخرى (الخو الدة، 2004)، كما فيأ أظهرت الدراسات أن الأسباب التي تمنع من استخدام التكنولوجيا في العملية التدريسية

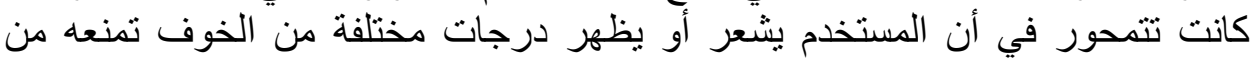
استخدام التكنولوجيا في التدريس. وقد عرفت (Russell, 1995) ست مر ساحل يمر بهات

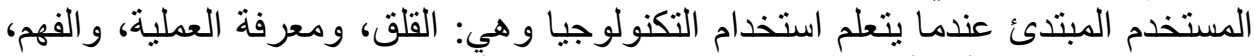

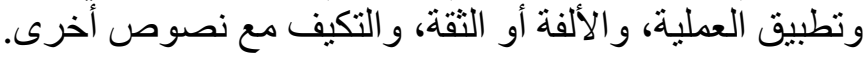

من ملاحظة الباحثون لبيئة التعلم الالكتروني في معظم الجامعات يوجد العديد من أهداف الاف الجات

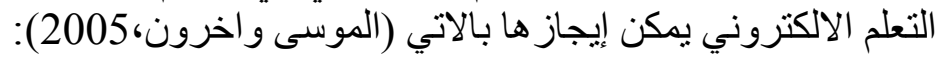

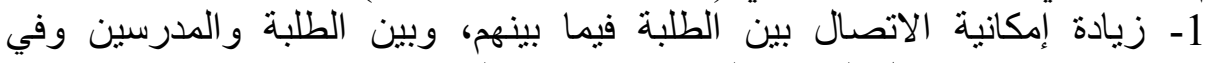

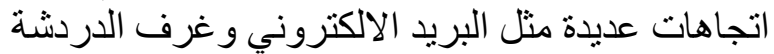

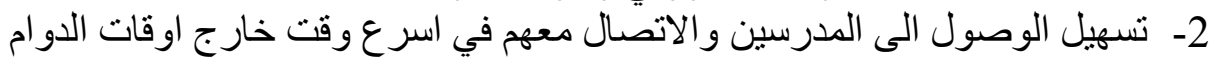
باستخدام الادوات التكنولوجية منل الايميل و عمليات النقاش عبر الانترنت

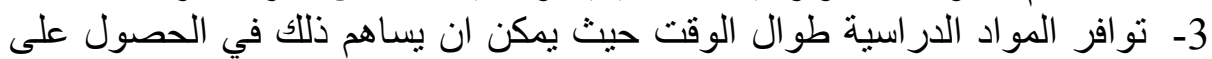

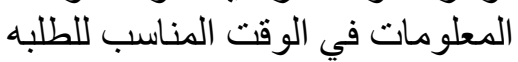

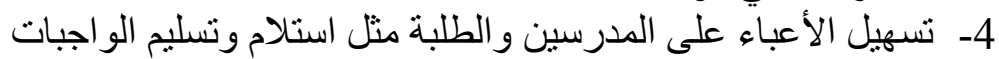

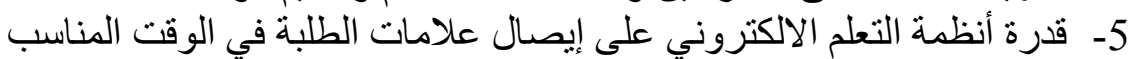

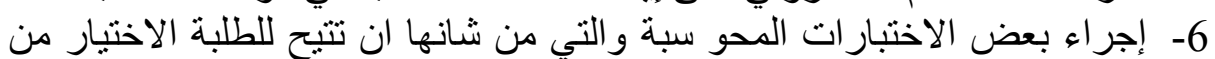


اما متطلبات التعلم الالكتروني فهي:

1- اشر الك جميع الوحدات والاقسام في بناء اسس تدريب الطلبه في التعامل مع انظمة

التعليم الالكتروني

2- بناء خطة لتسهيل عملية تعامل الطلبة مع منظومة التعليم الالكتروني

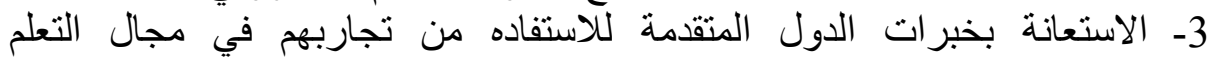

الالكتروني

4- تو افر البنية التحتية الضرورية اللازمة لتبال المعلومات بين الطلبة و المدرسين

اما عن أنواع التعلم الالكتروني فهي:

1- التعلم الالكتروني المباثر المتزاني: المني: ويعني اسلوب التعلم المعتمد على الثبكه

العالمية للمعلومات وتقنياته لتوصيل المقرارت وتبادلها، ومواضن واضع الابحاث بين

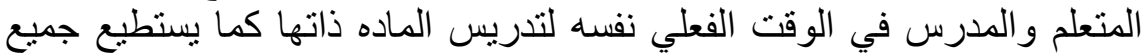
الطلبه التفاعل مع بعضهم بشكل مباشر ومع المدرس في نفس الوقته، ويتضمن فئن

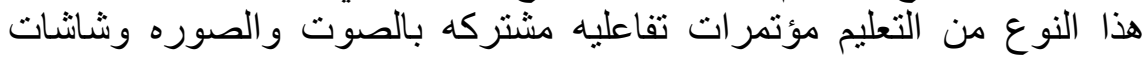

$$
\text { مشتركه. - مذاع }
$$

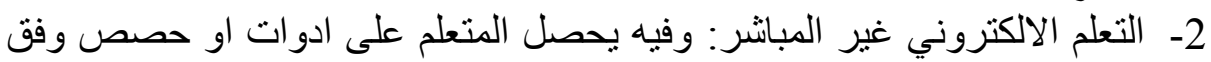

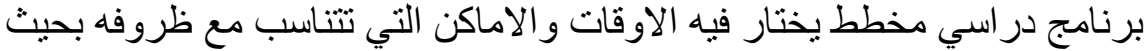

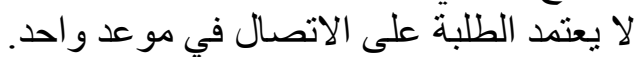

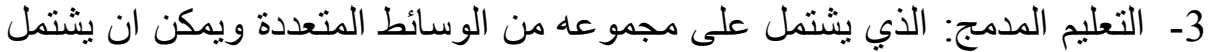

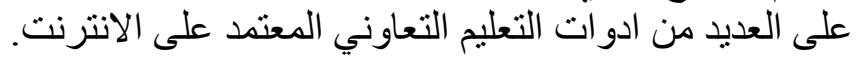

\section{ما يميز الاراسة الحالية عن الدراسات السابقة}

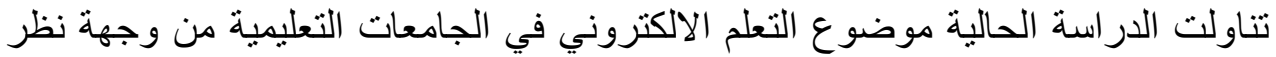

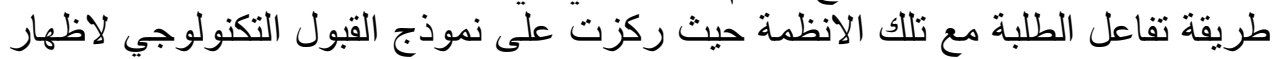

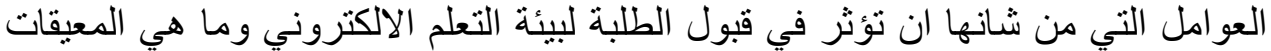

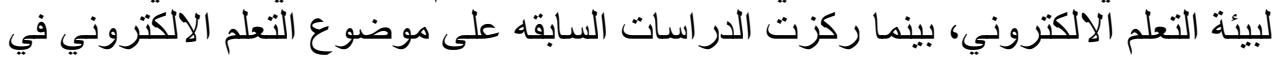

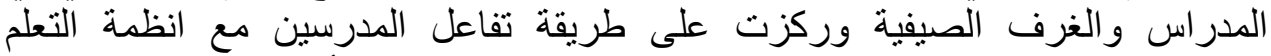
الالكتروني حيث ناقتت الموضوع ضمن المعيقات و السلبيات التي أثرت على تفاعل الطلبة

و المدرسين مع انظمة التعلم الالكتروني. نموذج الدراسنة

تم تصميم نموذج الدر اسة بالا عتماد على مجمو عة من الدر اسات السابقة حيث تم الاعتماد

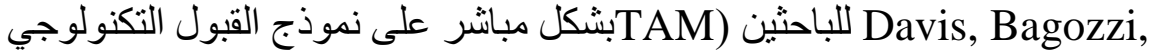

\&Warshaw, و ايضا تم الاعتماد على در اسة (Clark, Jones \& Zmud,

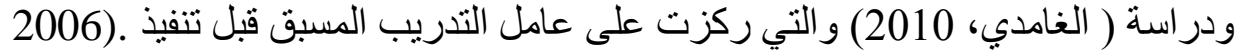

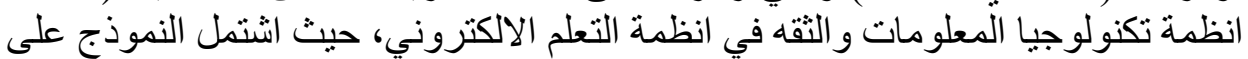

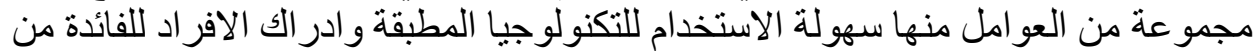

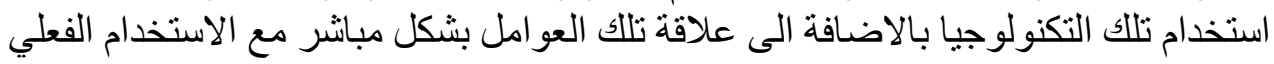


للتكنولوجيا المطبقة من خلال الاتجاه المبدئي للأفر اد والنية الاكيدة نحو استخدام تكنولوجيا

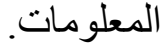

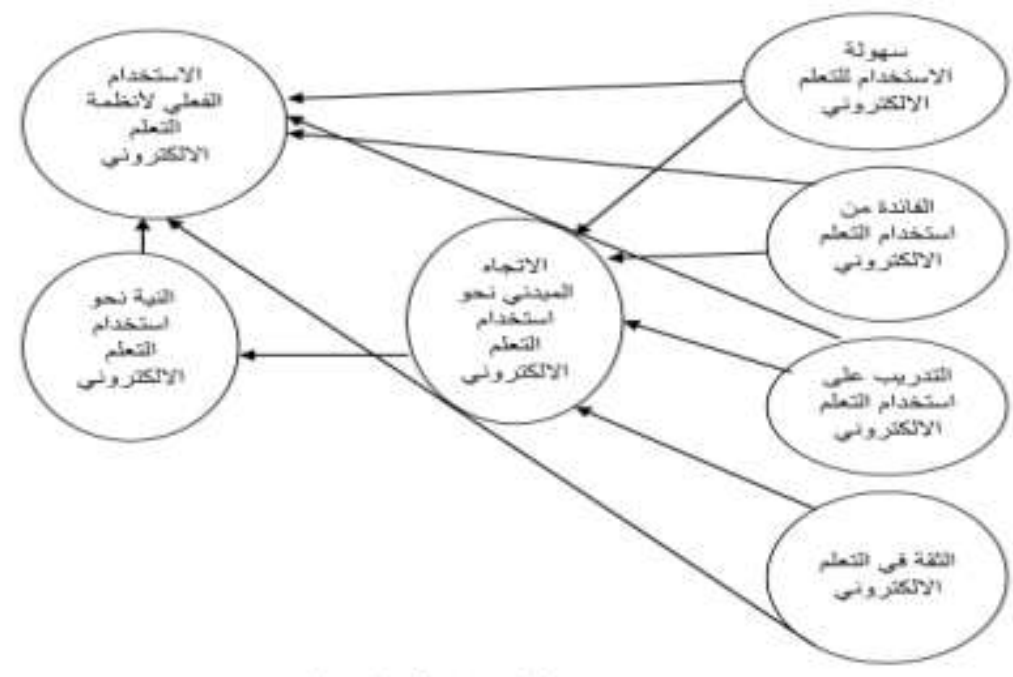

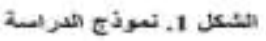

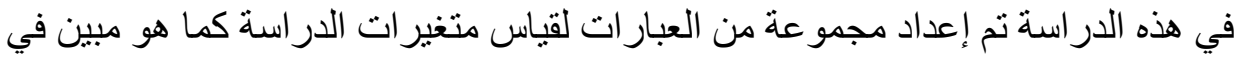

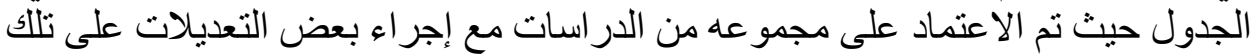

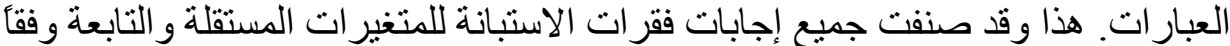

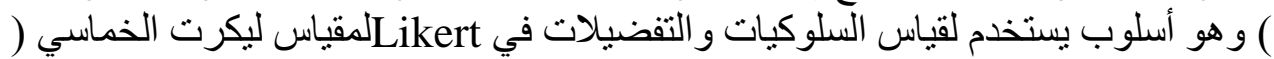
). ويعتمد Likert, 1932 (الاستبيانات وبخاصة في مجال در اسة سلوك المستخدمين (

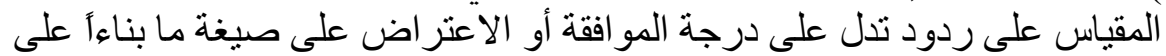

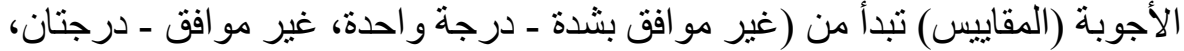

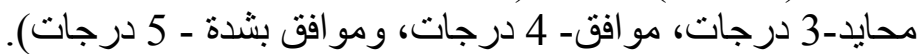
جدول 1. متغيرات الدراسة و و وعبار اتها

\begin{tabular}{|c|c|}
\hline العبارات & متغيرات الدراسة \\
\hline التعلم الالكتروني سهل الاستخدام & \multirow{4}{*}{ (Porter,C., and Donthu, N., 2006) } \\
\hline التعلم الالكتروني و اضح ومفهوم & \\
\hline استخر اج المعلومتي سهل من الانتركن الطلبة من & \\
\hline الاستى جميع الأحوال، التعلم الالكتروني سهل & \\
\hline على زياعد استخدام أنظة الفهم والاستيعاب للمساقات الالكتروني & 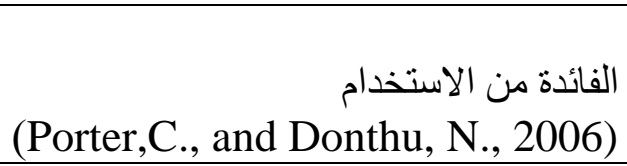 \\
\hline
\end{tabular}




\begin{tabular}{|c|c|}
\hline 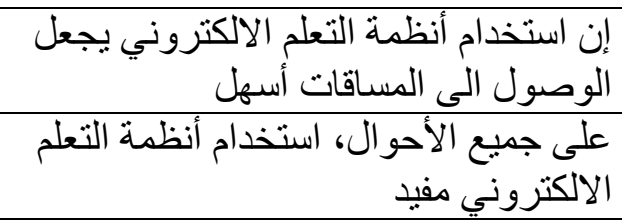 & \\
\hline 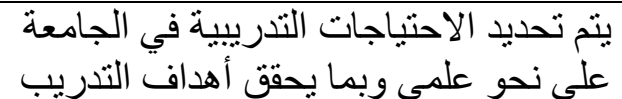 & \multirow{4}{*}{ 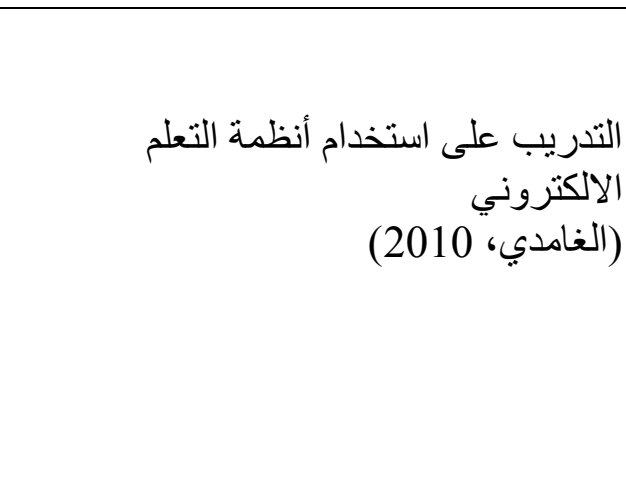 } \\
\hline 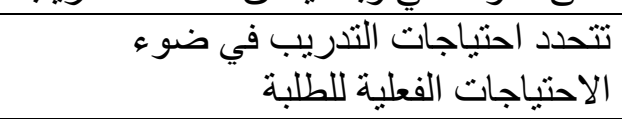 & \\
\hline الخشكلات لدور التدريبية بصريية تساعدره أفضل على حل & \\
\hline في أدائي التدريب سوف يؤدي الى إحداث تطوير & \\
\hline الأدو التعلم التالكتروني يجب معي ان يكون احد أهم & \multirow[t]{4}{*}{ 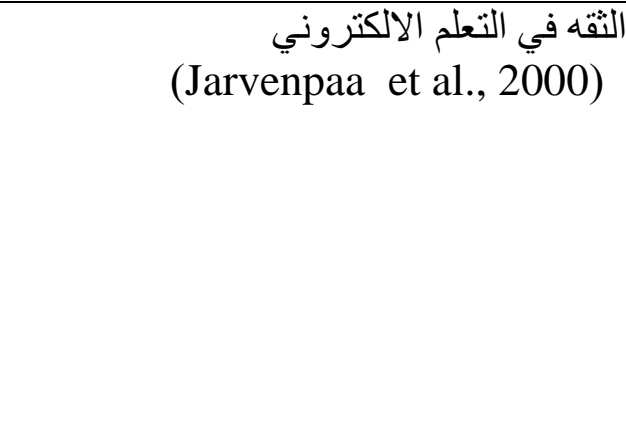 } \\
\hline أنا أثق في التعلم الالكتروني لأنه يسهل & \\
\hline تو قعاتي و احتياجاتي التعلئيمية التعامل معه يلبي & \\
\hline تقديم الخدمة لأكي طَّلب لالب يمكنم ان يتو انى عن & \\
\hline الالكتروني ايجابي اتجاه استخدام أنظمة التعلم & \multirow{3}{*}{$\begin{array}{r}\text { الالكتروني المبئي نحو استخدام انظمة التعلم } \\
\text { (Porter,C., and Donthu, N., 2006) }\end{array}$} \\
\hline إلن استخدات مفهومه أنظمة التعلم ألالكتروني تجعل & \\
\hline يجب ان أنتنى أنظمة التعلم الالكتروني & \\
\hline 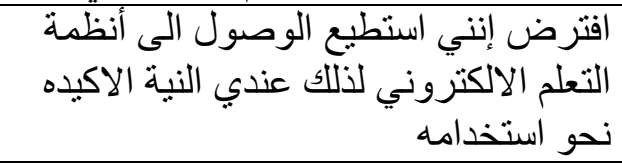 & \multirow{3}{*}{ 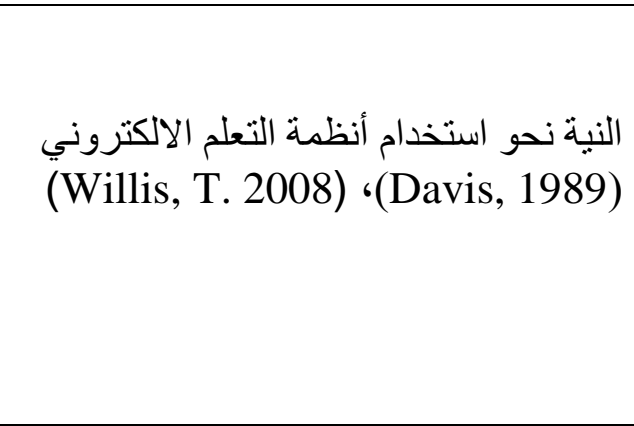 } \\
\hline 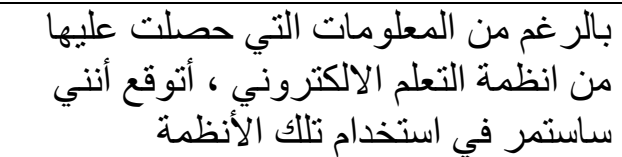 & \\
\hline لالأكترونية الآكيده نحو استخدام انظمة التعلم & \\
\hline الأحتخان لفو ائد شخصية التعلم الالكتروني في بعض & \multirow[t]{2}{*}{$\begin{array}{c}\text { الاستخدام الفعلي لأنظمة التعلم الالكتروني (Porter,C., and Donthu, N. 2006) } \\
\text { (Porthu }\end{array}$} \\
\hline امضي وقت طويل لاستخدام انظمة التعلم & \\
\hline
\end{tabular}




\section{الالكتروني لإغر اض شخصية تعليمية

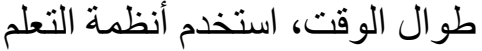 \\ الالكتروني لأغر اض شخص الخصية تعليمية}

\section{منهجية الاراسة}

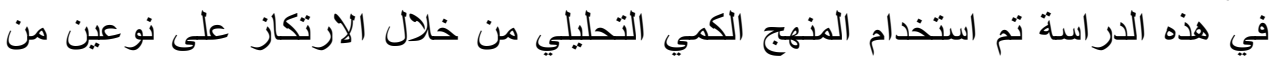

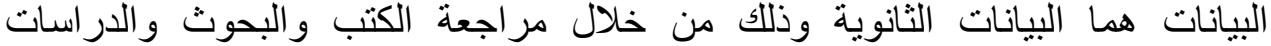

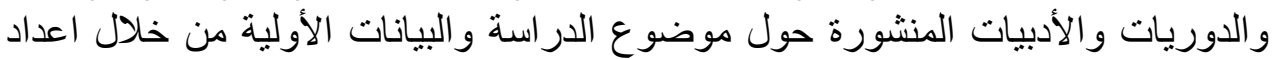

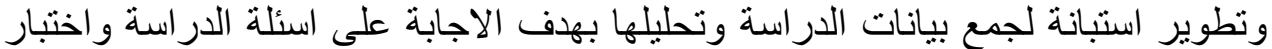

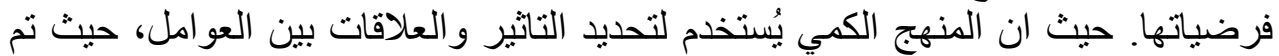

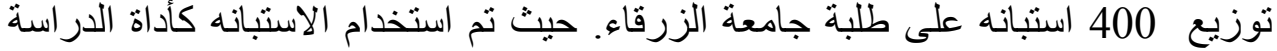
لجمع البيانات من طلبة الجامعة الذين يستخدمون انظمة التعلم الالكتروني بالمساقات التدريسية.

\section{مجتمع الاراسة وعينتها}

تكون مجتمع الدر اسة من طلبة جامعة الزرقاء في الأبهاء الاردن المكون من 7900 طالب، اما

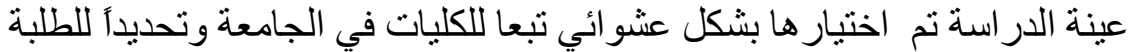

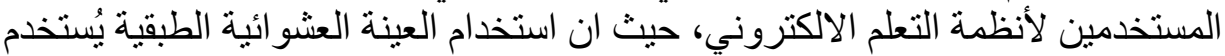

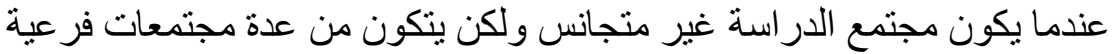

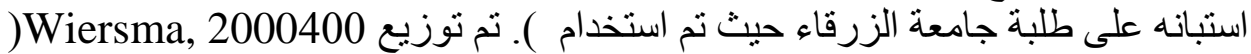

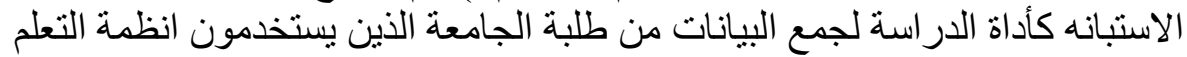

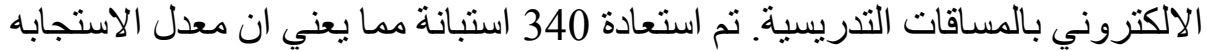

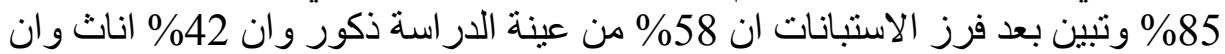

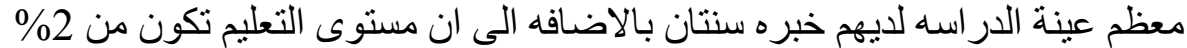

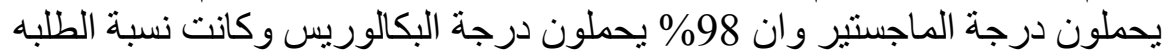

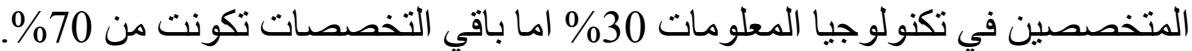
ويوضح الجدول التالي ملخص معدل الاستجابات.

جدول 2. ملخص معدل الاستجابات

\begin{tabular}{|c|c|}
\hline 400 & عدد الاستبيانات \\
\hline 40 & لم تستلم \\
\hline 20 & غير مكتملة \\
\hline 340 & مجموع الاستبيانات التي استلمت \\
\hline $85 \%$ & (3400) معدل الاستجابة \\
\hline
\end{tabular}

\section{اختبار صدق الأداة وثباتها}

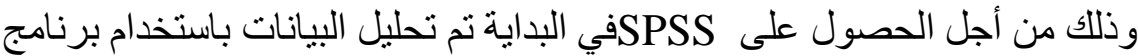

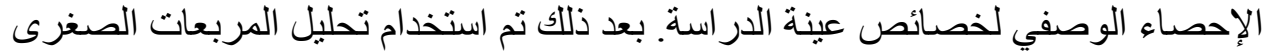

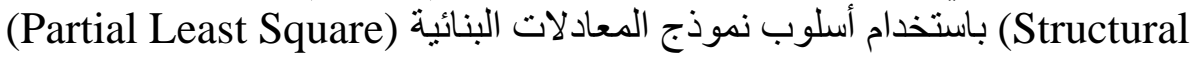




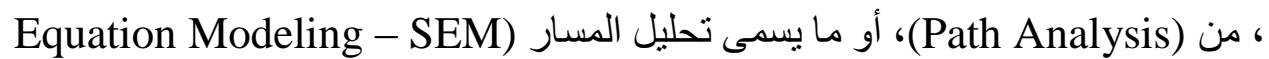

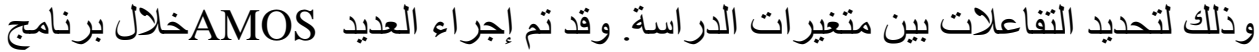

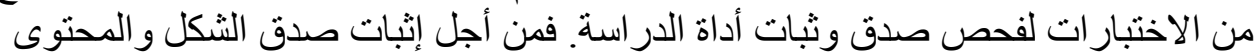

فقد تم عرض الاستبانة الأولية على عدد من Face and Content Validity)

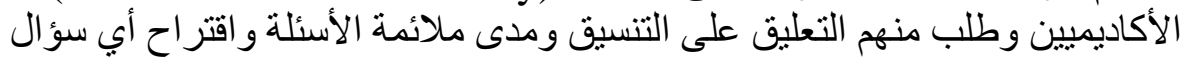

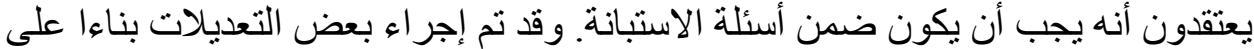

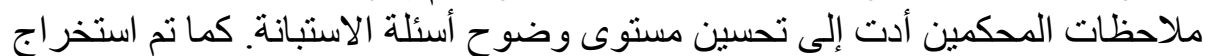

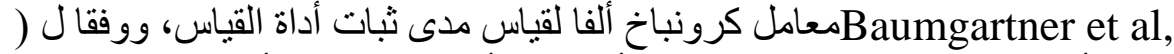

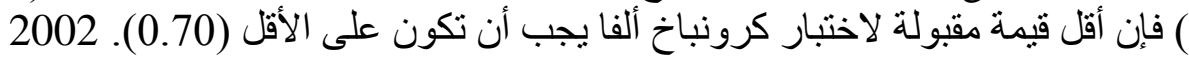

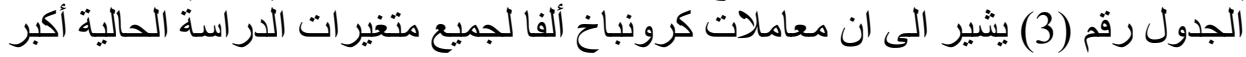
من 0.70 و هي قيم تعكس اتساقأ مناسبأ وكافياً لإجر اء هذاء الفاء الدر اسة.

\begin{tabular}{|c|c|c|}
\hline \multicolumn{3}{|c|}{ جدول 3. الموثوقية للاراسة } \\
\hline قيم كرونباخ & العبارات & اسم المتغير \\
\hline 0.81 & 4 & سهولة الاستخدام للتعلم الالكتروني \\
\hline 0.90 & 3 & الفائدة من استخدام التعلم الالكتروني \\
\hline 0.77 & 5 & الالكترونيب على استخدام التعلم \\
\hline 0.85 & 4 & الثقة في استخدام التعلم الالكتروني \\
\hline 0.75 & 3 & الالكتروني المبدئي نحو استخدام التعلم \\
\hline 0.91 & 3 & النية نحو استخدام التعلم الالكتروني \\
\hline 0.91 & 3 & الاستخدام الفعلي للتعلم الالكتروني \\
\hline & 25 & المجموع \\
\hline
\end{tabular}

كما في (Confirmatory Factor Analysis)تم استخدام التحليل العاملي التأكيدي

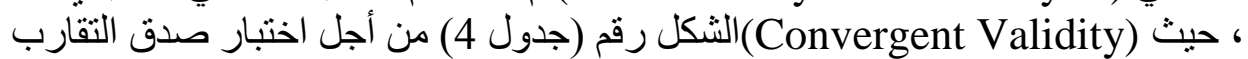
كان التحميل المعياري لمعظم مفردات الاستبانة أكبر من الحد الأدنى المقترح (0.50)

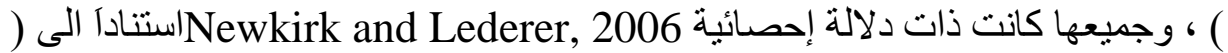
وبالتالي 4). كما هنالك شو اهد قوية على وجود صدق التقارب للأسئلة التي تقيس كل متغير (جدول (Average Variance Extracted - AVE)

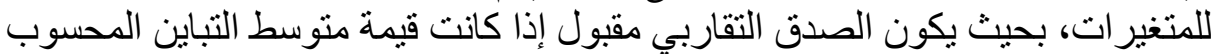

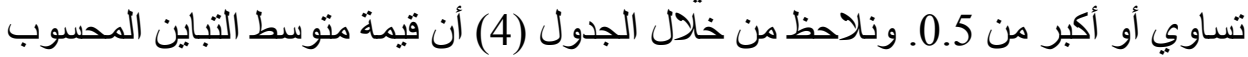

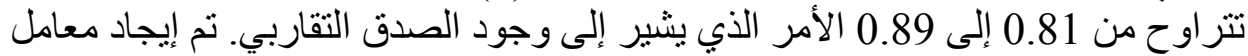

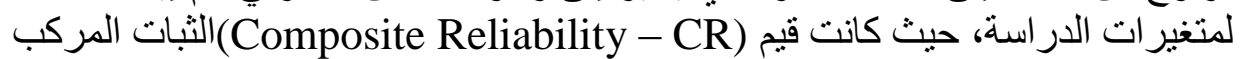




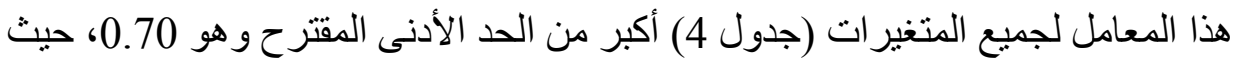

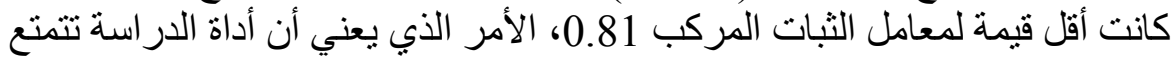

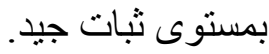

\begin{tabular}{|c|c|c|c|c|c|}
\hline $\begin{array}{l}\text { متوسط التباين } \\
\text { AVE }\end{array}$ & 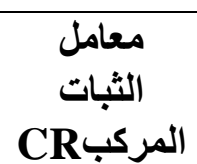 & كرونباخ & تباين & المعياريل & المتغير \\
\hline \multirow[t]{4}{*}{0.88} & 0.85 & 0.94 & & & سهولة الاستخدام \\
\hline & & & 0.343 & 0.631 & EU2 \\
\hline & & & 0.213 & 0.531 & EU3 \\
\hline & & & 0.133 & 0.521 & EU4 \\
\hline \multirow[t]{3}{*}{0.82} & 0.92 & 0.86 & & & الفائدة \\
\hline & & & 0.236 & 0.526 & UF1 \\
\hline & & & 0.322 & 0.637 & UF2 \\
\hline \multirow[t]{5}{*}{0.77} & 0.81 & 0.72 & & & التدريب \\
\hline & & & 0.302 & 0.671 & TR1 \\
\hline & & & 0.157 & 0.635 & TR2 \\
\hline & & & 0.125 & 0.503 & TR3 \\
\hline & & & 0.155 & 0.514 & TR5 \\
\hline \multirow[t]{3}{*}{0.89} & 0.91 & 0.93 & & & الثقة \\
\hline & & & 0.323 & 0.512 & TS1 \\
\hline & & & 0.383 & 0.527 & TS3 \\
\hline \multirow[t]{4}{*}{0.83} & 0.84 & 0.76 & 0.420 & & الاتجاه \\
\hline & & & 0.122 & 0.524 & AT1 \\
\hline & & & 0.242 & 0.722 & AT2 \\
\hline & & & 0.163 & 0.522 & AT3 \\
\hline \multirow[t]{4}{*}{0.81} & 0.85 & 0.74 & 0.320 & & النيه \\
\hline & & & 0.324 & 0.551 & In1 \\
\hline & & & 0.142 & 0.513 & In2 \\
\hline & & & 0.235 & 0.521 & In3 \\
\hline \multirow[t]{4}{*}{0.87} & 0.91 & 0.85 & 0.320 & & الاستخدام الفعلي \\
\hline & & & 0.488 & 0.531 & AU1 \\
\hline & & & 0.381 & 0.545 & AU2 \\
\hline & & & 0.105 & 0.171 & AU3 \\
\hline
\end{tabular}

كما يشير الجدول رقم (5) إلى أن الجذور التربيعية لقيم منوسط التباين المحسوب

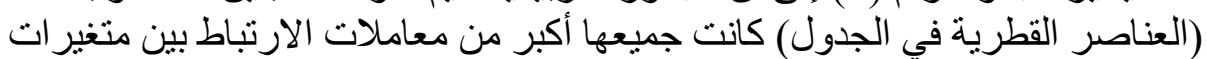

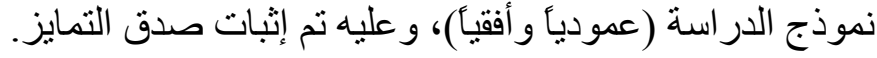


جدول 5. معاملات الارتباطوالجذر التربيعي لمتوسط التباين المحسوب

\begin{tabular}{|c|c|c|c|c|c|c|c|}
\hline الاستخلي & النية & الاتجاه & الثقة & التدريب & الفائدة & سلاستخدام & \\
\hline & & & & & & 0.88 & الاستخولة \\
\hline & & & & & 0.82 & 0.26 & الفائدة \\
\hline & & & & 0.77 & 0.40 & 0.12 & التدريب \\
\hline & & & 0.89 & 0.26 & 0.12 & 0.25 & الثقة \\
\hline & & 0.83 & 0.14 & 0.26 & 0.13 & 0.34 & الاتجاه \\
\hline & 0.81 & 0.38 & 0.17 & 0.21 & 0.25 & 0.12 & النية \\
\hline 0.87 & 0.32 & 0.43 & 0.27 & 0.20 & 0.22 & 0.15 & الاستخلى ام \\
\hline
\end{tabular}

\section{تحليل البيانات}

(Structural Equation

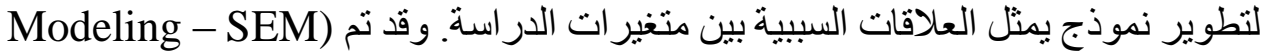

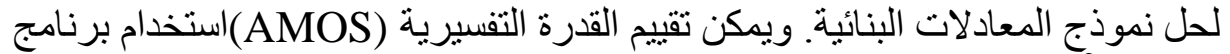

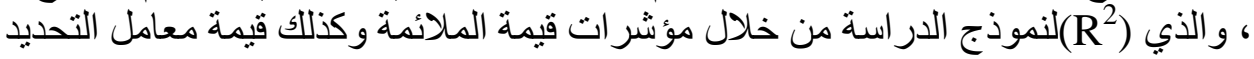

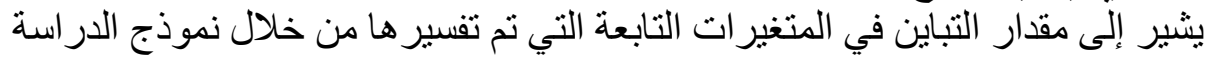

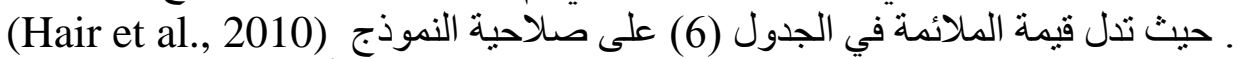

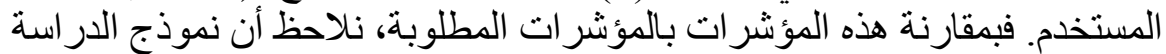

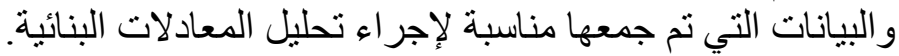

جدول 6. مؤشرات قيمة الملائمة

\begin{tabular}{|c|c|c|}
\hline القيمة الفعلية & | القيمة المطلوبةة* & المؤشر ات \\
\hline 2.32 & $>3$ & مربع كاي النسبي (x²/DF) \\
\hline 0.834 & $0.90<$ & جودة الصلاحية (GFI) \\
\hline 0.862 & $0.80<$ & جودة الصلاحية المعدلة \\
\hline 0.825 & $0.90<$ & مؤشر الصلاحية المعياري (NFI) \\
\hline 0.895 & $0.90<$ & (CFI) مؤشر الصلاحية المقارن \\
\hline 0.833 & $0.90<$ & ) مؤشر الصلاحية التدريجي (IFI) \\
\hline 0.050 & 0.08 إلى 0.05 & جذر منوسط مربع الخطأ للتقريب (RMSEA) \\
\hline
\end{tabular}

Schumacker and Lomax (2004) 
يظهر الثكل رقم (7) النموذج النهائي للعلاقات بين جميع متغير ات الدر اسة. كما يشير

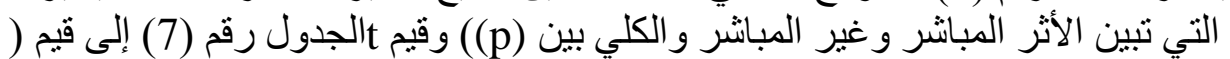

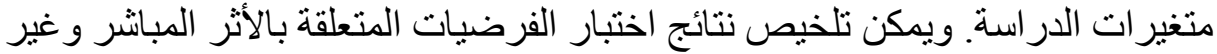

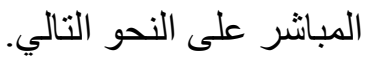

جدول 7. نتائج اختبر فرضيات النموذج (الأثر المباشر وغير المباشر)

\begin{tabular}{|c|c|c|c|}
\hline الاليل العملي & p معاملات & قيم t & المسار المفترض \\
\hline مقبولة & 0.021 & 2.152 & AT $<$ \\
\hline مقبولة & 0.015 & 2.250 & AT $<$ \\
\hline مقبولة & 0.002 & 2.415 & AT $\prec$ \\
\hline مقبولة & 0.024 & 2.311 & AT $\prec$ \\
\hline مقبولة & 0.011 & 6.226 & $\mathbf{I N}<$ \\
\hline مقبولة & 0.022 & 2.212 & $\mathbf{A U}<\longleftarrow$ \\
\hline غير مقبولة & 0.823 & 1.736 & $\mathbf{A U} \prec$ \\
\hline مقبولة & 0.001 & 2.012 & $\mathbf{A U}<$ \\
\hline غير مقبولة & 0.114 & 1.014 & $\mathbf{A U} \prec$ \\
\hline غير مقبولة & 0.614 & 1.010 & $\mathbf{A U} \prec$ \\
\hline
\end{tabular}

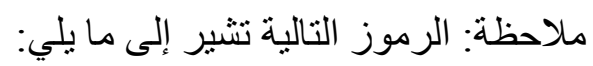
EU الفائدة: UF TR - T - T التدريب :TR TS الاتجاه: AT (النية: AT الاستخدام الفعلي : (النة: AU

يؤثر سهولة الاستخدام بشكل إيجابي مباثر على الاتجاه المبدئي لانظمة التعلم الالكتروني

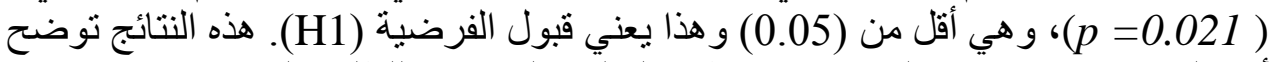

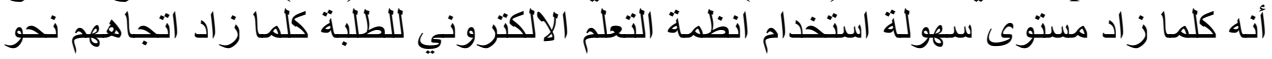




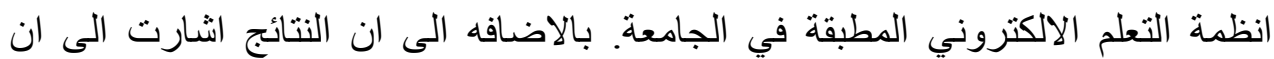

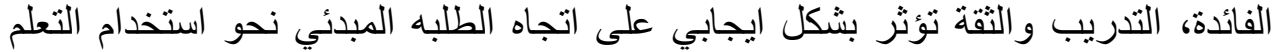
الالكتروني كما وضحت النتائج على التوالي (0.0)

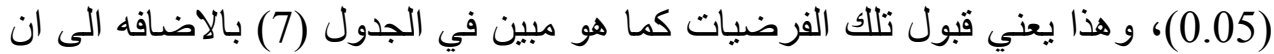

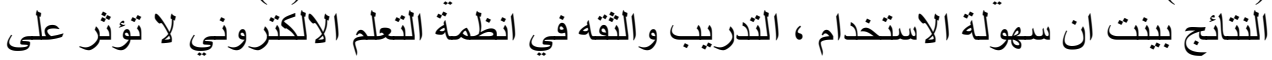

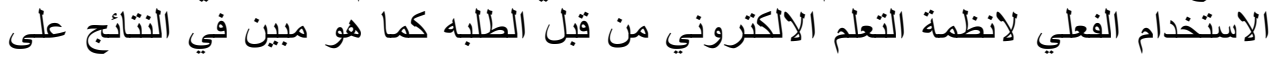
التوالي (

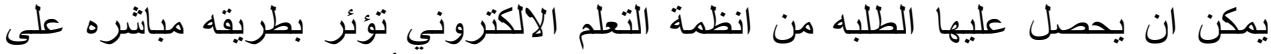

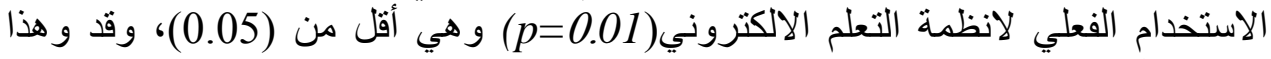
يعني قبول تلاك الفرضيه.

\section{الأثر الوسيط}

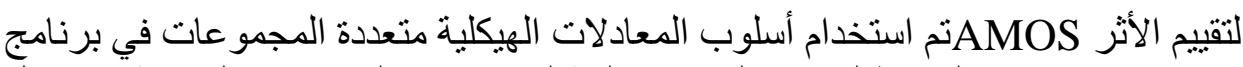

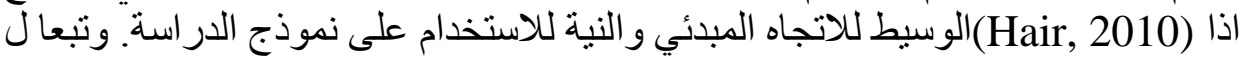

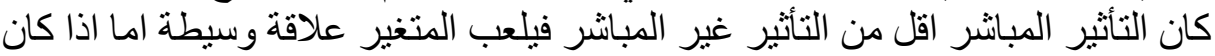

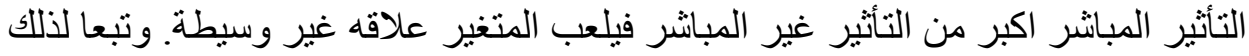

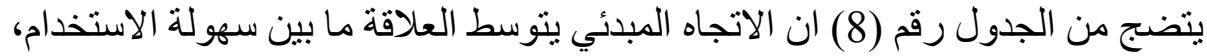

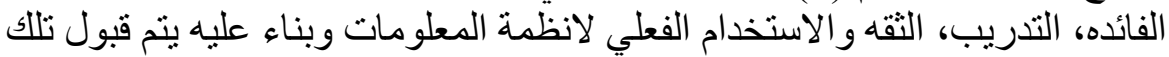

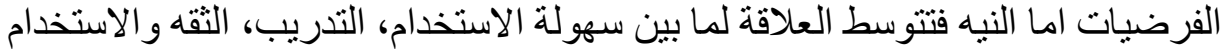

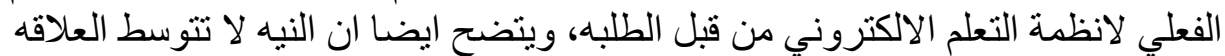
بين الفائده والاستخدام الفعلي لانظمة التعلم الالكتروني كما هو موضح في الجندي الندول رقم

جدول 8. الأثر الوسيط للاتجاه والنية

\begin{tabular}{|c|c|c|c|c|c|c|c|}
\hline الأثخ الوسيط & الأثتـــــ & الأثـــــر غبــــر & 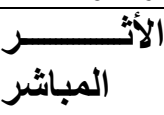 & الى |لى & العامــــــــل & من & الفرضيات \\
\hline وسيط & 0.057 & 0.036 & 0.021 & AU & AT & EU & H11 \\
\hline وسيط & 0.007 & 0.004 & 0.003 & $\mathrm{AU}$ & AT & UF & H12 \\
\hline وسيط & 0.036 & 0.031 & 0.005 & AU & AT & TR & H13 \\
\hline
\end{tabular}


Determinants of the Actual Use of E-Learning Systems

\begin{tabular}{|c|c|c|c|c|c|c|c|}
\hline وسيط & 0.121 & 0.065 & 0.056 & AU & AT & TS & H14 \\
\hline وسيط & 0.062 & 0.041 & 0.021 & AU & IN & EU & H15 \\
\hline غبر وسيط & 0.454 & 0.112 & 0.342 & AU & IN & UF & H16 \\
\hline وسيط & 0.085 & 0.074 & 0.011 & AU & IN & TR & H17 \\
\hline & 0.035 & 0.023 & 0.012 & AU & IN & TS & H18 \\
\hline
\end{tabular}

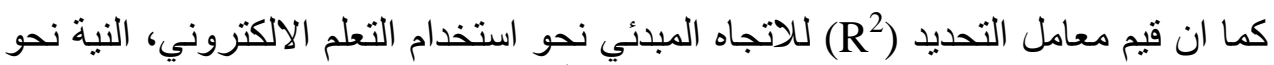

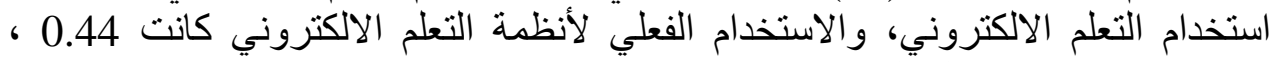
0.49 ، و 0.65 على التعلم الاكتروني.

\section{مناقشة النتائج و التوصيات}

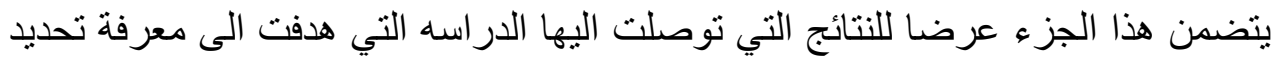

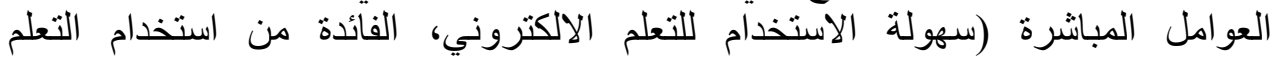

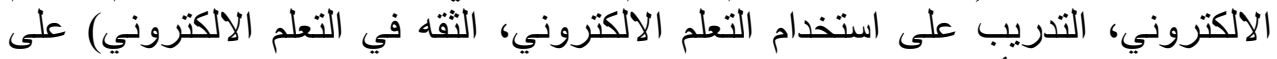

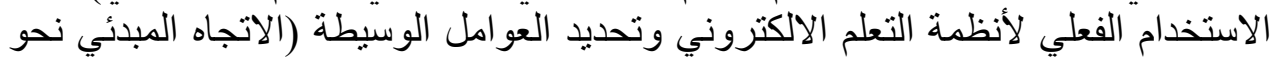

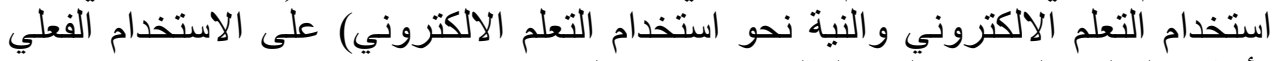
لأنظمة التعلم الالكتروني لَّى الطلبة في جامعة الزرقاء التطاء في الاردن.

\section{نتائج الاراسة}

في ضو ءنتائج اجابات اسئلة الدراسة واختبار فرضياتها فقد نم التوصل الى النتائج الآتية:

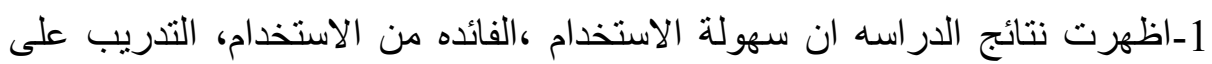

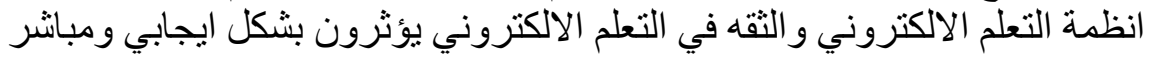
على اتجاه طلبة جامعة الزرقاء للتعلم الالكتروني. 


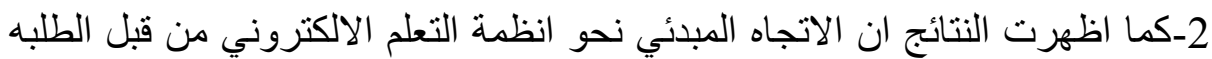
يؤثر بشكل ايجابي ومباثر على النيه الاكيده في استخدام الطلبه لانظمة النعلم الني

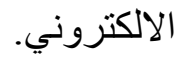
3-بعد النيه الاكيده ل لاستخدام الطلبه لانظمة التعلم الالكتروني يؤثر بشكل ايجابي

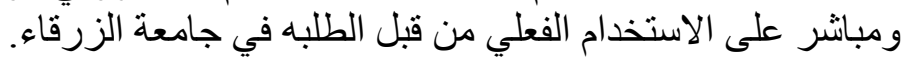

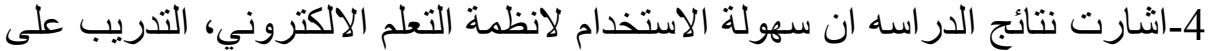

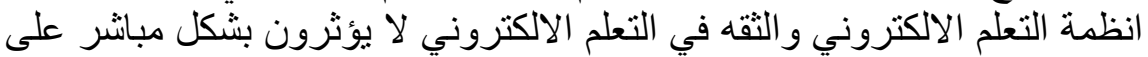

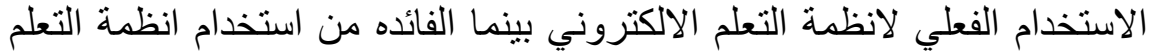
الالكتروني من قبل الطلبه تؤثر بشكل ايجابي على الاستخدام الفعلي لانظمة التعلم التطل

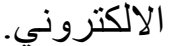

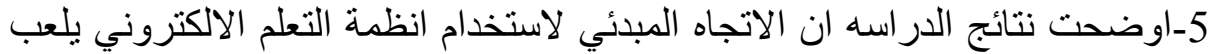

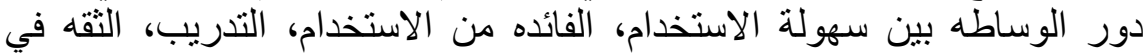
انظمة التعلم الالكتروني والاستخدام الفعلي لانظمة التعلم الالكتروني من قبل طلبة الأل جامعة الزرقاء في معظم التخصصات.

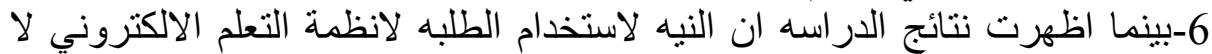

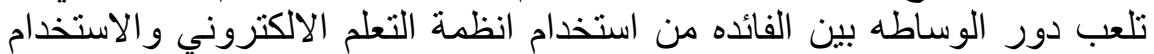

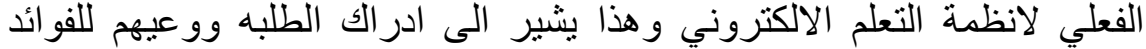
المبانره التي يمكن الحصول عليها من الاستخدام الفعلي لانظمة التعلم الالكتروني

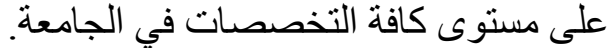

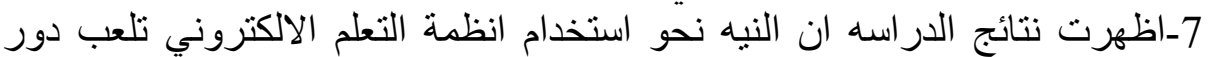

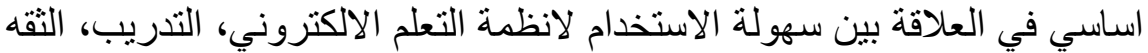
في انظمة التعلم الالكتروني و الاستخدام الفعلي لانظمة التعلم الالكتروني من قبل التيل

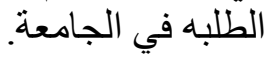

\section{توصيات الاراسة}

في ضوء النتائج السابقه توصي الدراسة الحالية بما يأتي:

1-تثجيع الطلبة على الانخراط و التسجيل في المواد التي يتم تدريسها بطريقة

$$
\text { الكترونية. }
$$

2-العمل على نشر الثقافة الالكترونية بين الطلبه ل لتحقيق أكبر قدر من التفاعل حول هذا النوع من التعليه. 3-عقد دورات تدريبية لاستخدام التعليم الالكتروني في الجامعة للطلبة ولأعضاء هيئة التدريس ايضاً. 4-ايجاد نشاطات مختلفة لا يمكن اتمامها الا من خلال استغلال انظمة التعلم

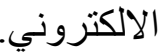
5-الاستمر ار في نطوير التعلم الاككتروني بما يتناسب مع حاجات ونوقعات الطلبة. 


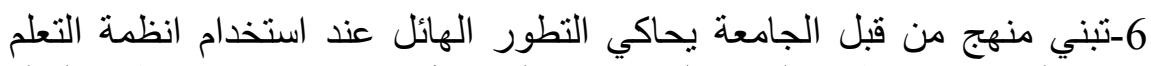

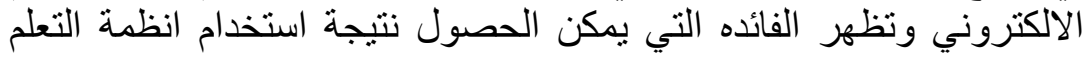

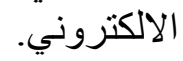

\section{دراسات مستقبلية}

في ضوء ما سبق توصي الدر اسة الحالية بما يلي:

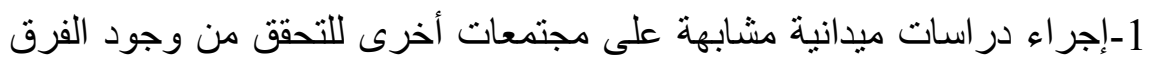

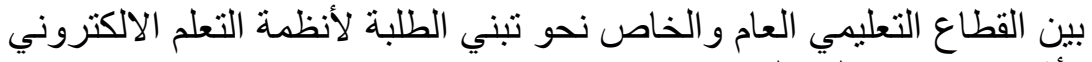

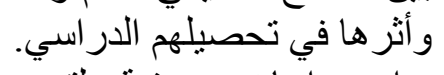

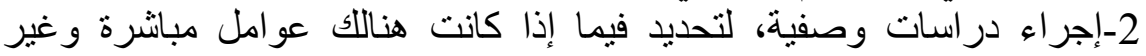

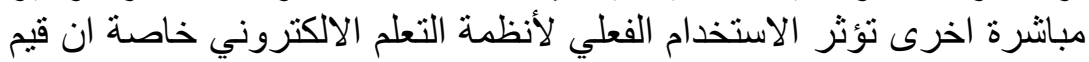

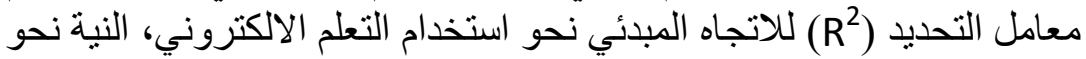

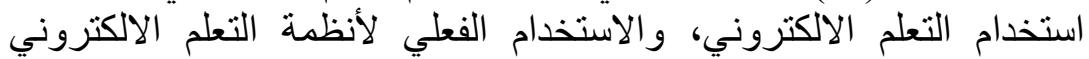

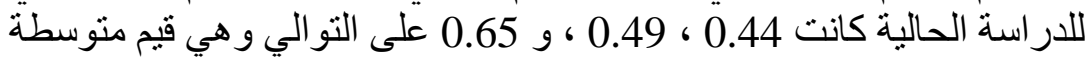
تدعو الباحثين لإجر اء المزيد من الابحاث العلمية بها المجال.

\section{3-المراجع العربية}

4-ابو موسى، م. (2008). اثر استخدام استراتيجية التعلم المزيج على فئل تحصيل

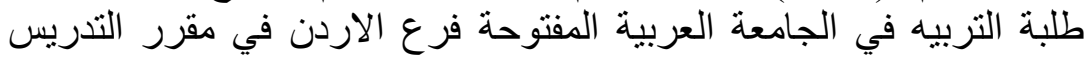

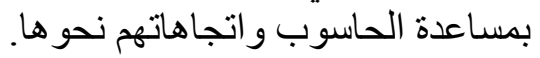

5-ابو يونس ،إ. (2000). فاعلية برنامج حاسوبي متعدد الوسائط لتدريس الهندسة

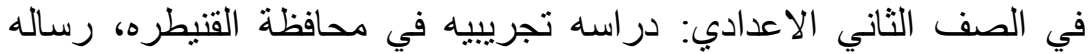

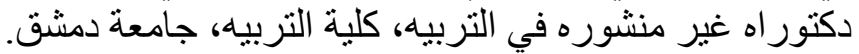

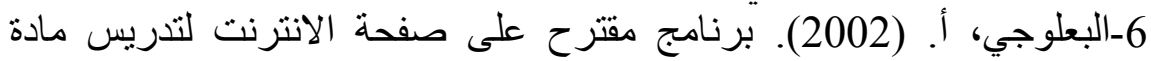

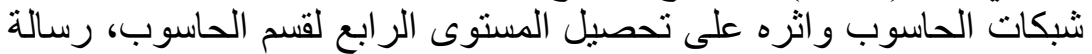

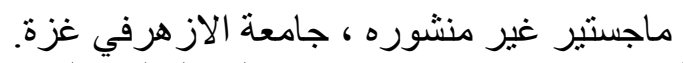

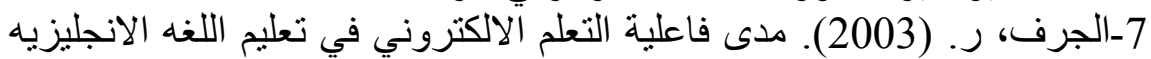

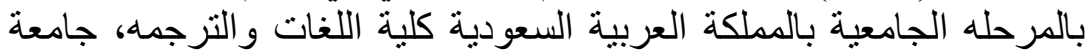

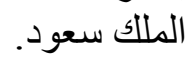

8_الجملان، م. (2004) ـ و اقع استخدام تكنولوجيا التعليم و المعلومات بمر اكز

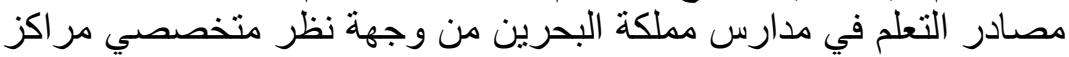

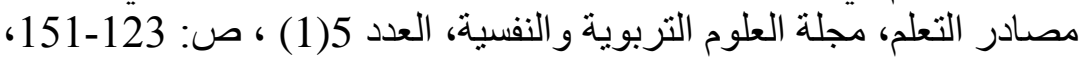

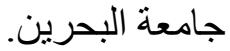

10-الحلفاوي، و. (2007) ـ مستحدثات تكنولوجيا التعليم في عصر المعلوماتية، 
12-الخو الدة، م. (2004) ـ أسس بناء المناهج التربوية وتصميم الكتاب التعليمي،

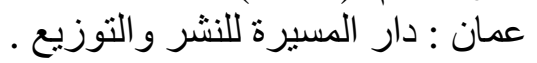

14-الثنايب، أ. (2001). و اقع استخدام اعضاء هيئة التدريس في الجامعات

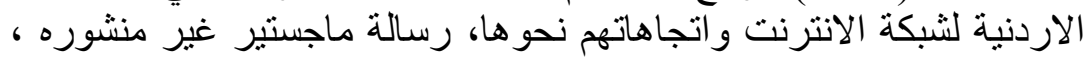
جامعة اليرموك، اربد، الارنئ الاردن. 15-الثربيني، أ وعبدالباسط، ي. الاردن (2003). تكنولوجيا الاتصالات الحديثه

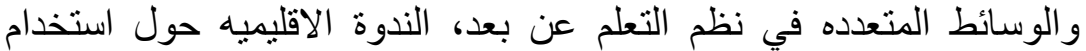

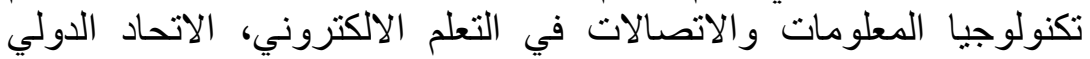

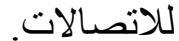

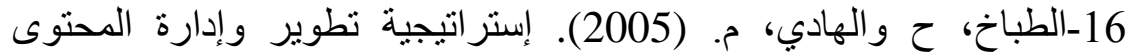

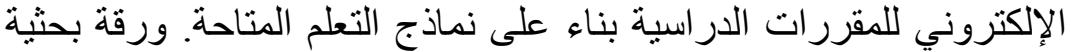

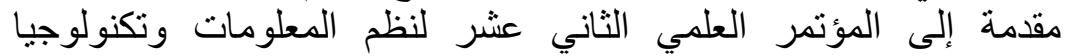
الحاسبات،17فبر اير ، أكاديمية السادات للعلوم الإدارية، القاهرة، 15.

18-الغامدي، خ. (2010). دور التدريب في رفع كفاءة اداء موظفي القطاع العام.

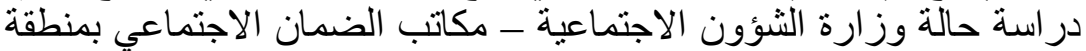
الباحه، رسالة ماجستير منشورة، السعودية.

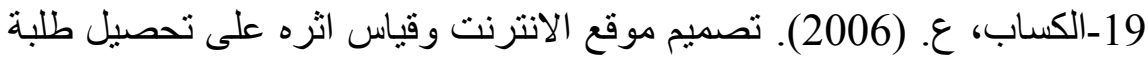

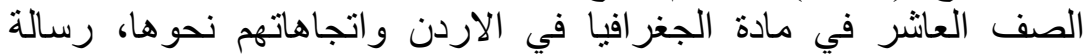
دكتور اه غير منشوره، الجامعة الاردنية، عمان، الإن الاردن.

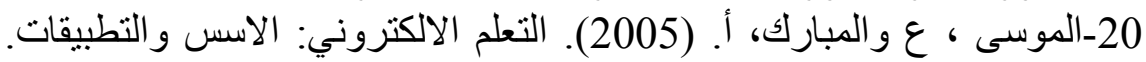

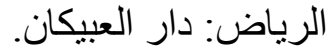

22-الهرش، ع. (1999). استخدام شبكة الانترنت من قبل اعضاء هيئة التدريس

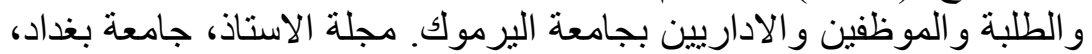

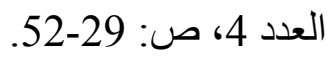

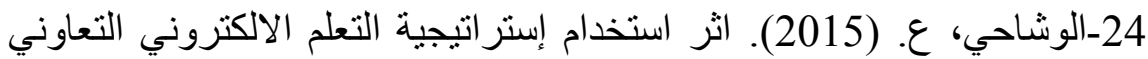

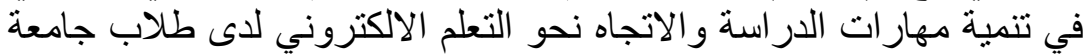

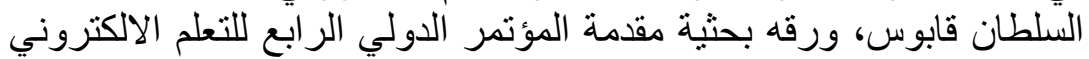

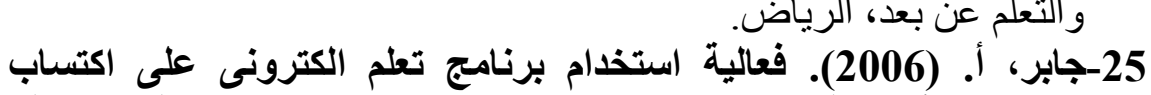

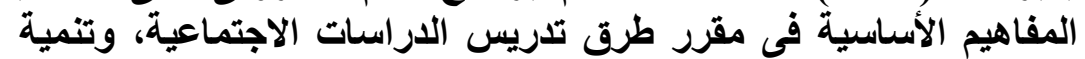

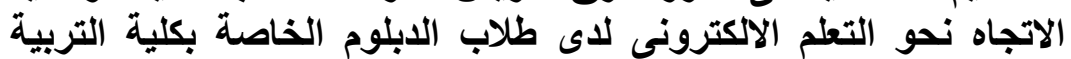

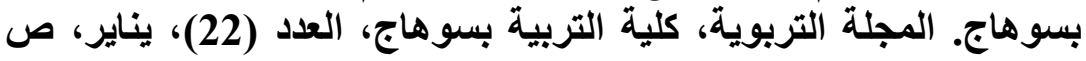

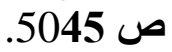


26-جمعاه، إ. (2000). فاعلية برنامج حاسوبي تفاعلي متعدد الوسائط في تحصيل

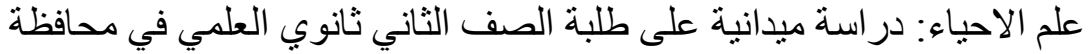

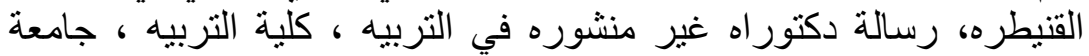

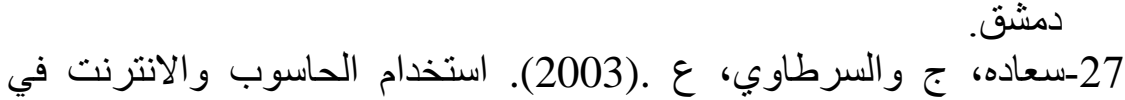

$$
\begin{aligned}
& \text { ميادين التربية والتعليم، دار الثنروق للنشر و التنوزيع. }
\end{aligned}
$$

29-صادق، ع. (2005). استعداد اعضاء هيئة التدريس بجامعة جنوب الوادي التئي

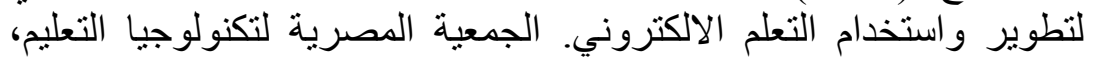

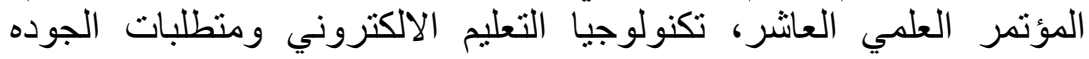

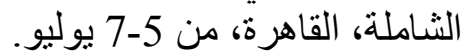

31-عبد العزيز، ح ـ(2008). التعليم الإلكتروني الفلسفةـ المبادئ- الأدواتالتطبيقات، عمان :دار الفكر.

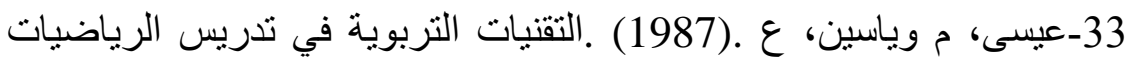

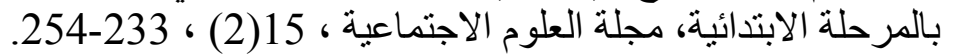

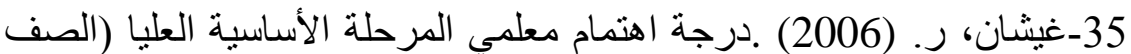

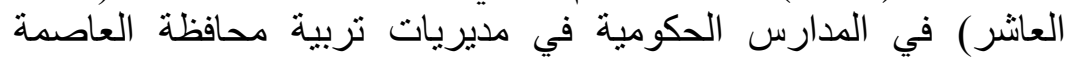

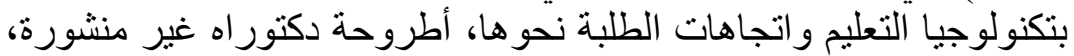
الجامعة الأردنية، عمان، الأردن.

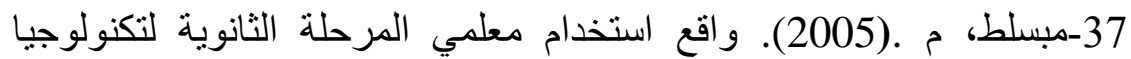

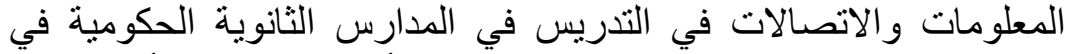

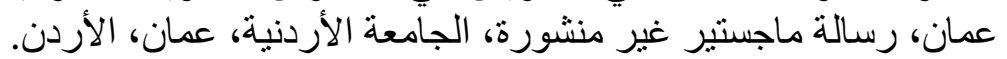

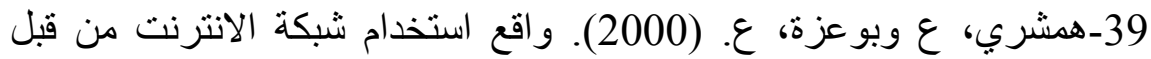

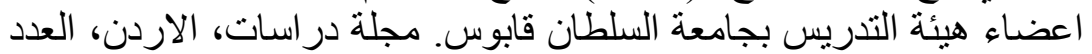

.342-328، (2)27

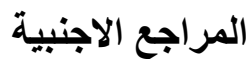

Alenezi, A., and Shahi, K. (2015). Interactive e-learning through second life with blackboard technology. Procedia Social and Behavioral Sciences, 176, 891-897.

Allehaibi, M. (2001). Faculty adoption of Internet technology in Saudi Arabian universities. $\mathrm{PhD}$, Florida State University. Available:

http://www.sssgrp.com/Menu/DissAbstracts/InnovationDiffusion/Allehaibi.htm. Retrieved on $12 / 4 / 2015$. 
Allen, I., and Seaman, J. (2004). Entering the mainstream: The quality and extent of online education in the United States, 2003 and 2004. Retrieved April 15, 2015 from: http://sloan-c.org/resources/entering mainstream.pdf.

Baumgartner, T., Strong, C., and Hensley, L. (2002). Conducting \& reading research in health \& human performance. 3th ed., New York: McGraw-Hill.

Clark, Jr. T.D., Jones, M.C., and Zmud, R.W. (2006). Post adoptive ERP system analysis: A system dynamic modeling approach, Working Paper, http://www.bus.lsu.edu./centers/decid/WorkingPaper.asp.

Compeau, D.R., Higgins, C.A., and Huff, S.L. (1999). Social cognitive theory and individual reactions to computing technology: A longitudinal study. MIS Quarterly, 23(2), $145-158$.

Davis, F. D. (1989). Perceived usefulness, perceived ease of use, and user acceptance of information technology. MIS Quarterly, 13(3), 319-340.

Davis, F., Bagozzi, R., and Warshaw, P. (1989). User acceptance of computer technology: A comparison of two theoretical models. Management Science, 35(8), 982-1003.

Diana, O. (1992). Teaching and learning with computers. (URL: http://orders.edrs.com).

Doll, W.J., Deng, X., and Scazzero, J.A. (2003). A process for post-implementation IT benchmarking. Information \& Management, 41, 199-212.

George, P. (2000). Breaking ranks. Principal Leadership, 1(4), 56-61.

Hair, J., Black, W., Babin, B., and Anderson, R. (2010). Multivariate data analysis. 7th ed., Prentice Hall, Upper Saddle River, New Jersey.

Imel, S. (1998). Myths and realities. (Report No. BBB16032). Columbus, OH. ERICClearinghouse on Adult, Career, and Vocational Education.

Jarvenpaa, S., Tractinsky, N., and Vitale, M. (2000). Consumer trust in an Internet store. Information Technology and Management, 1(1) 45-71.

Koohang, A. (2004). A study of users' perceptions toward e- learning courseware usability. International Journal on E- Learning, 3(2), 10- 17.

Kulik, J. A., and Kulik, C. L. (1991). Effectiveness of computer-based instruction. Computers in Human Behavior, 7(1), 75-94.

Likert, R. (1932). A technique for the measurement of attitudes. Archives of Psychology, 140, 1-55.

Masa'deh, R., Shannak, R., and Maqableh, M. (2013). A structural equation modeling approach for determining antecedents and outcomes of students' attitude toward mobile commerce adoption. Life Science Journal, 10(4), 2321-2333. 
Masa'deh, R., Tarhini, A., Bany Mohammed, A., and Maqableh, M. (2016). Modeling factors affecting student's usage behaviour of e-learning systems in Lebanon. International Journal of Business and Management, 11(2), 299-312.

Mickelson, R., and Stephen S. (1999). Race, tracking, and achievement among AfricanAmericans in a desegregated school system: Evidence from the Charlotte- Mecklenburg schools. Paper prepared for the Stanford University Conference on Race African Americans: Research and Policy Perspectives at the Turn of the Century.

Newkirk, H., and Lederer, A. (2006). The effectiveness of strategic information systems planning under environmental uncertainty. Information \& Management, 43, 481-501.

Paris, P. (2004). E- Learning: A study on secondary students' attitudes towards online web assisted learning. International Education Journal, 5(1), 98-112.

Park, J. (2005). The relationship between computer attitudes, usability and transfer of training in e-learning settings. PHD.University of Illinois, Available at Http: // www.lib.umi.com/dessertation/ preview- all/ 3182345. (Retrieved on January 2016).

Porter,C and Donthu,N. (2006) . Using the technology acceptance model to explain how attitudes determine Internet usage: The role of perceived access barriers and demographics. Journal of Business Research, 59, 999-1007.

Russell, A. I. (1995). Stages in learning new technology: Naïve adult e-mail users. Computers in Education, 25(4), 173-178.

Schumacker, R. E., and Lomax, R. G. (2004). A beginner's guide to structural equation modeling (2nd ed.). Mahwah, NJ: Lawrence Erlbaum Associates, Inc.

Stoehl, L., and Lee, K. (2003). Modeling the effect of experience on student acceptance of Web-based courseware. Internet Research: Electronic Networking Applications and Policy, 13(5), 364-374.

Swan, M.B. (2005). Improving learning in mathematics: Resources for teaching, multimedia resource. Professional Development Guide.

Tarhini, A., Hone, K., and Liu, X. (2013). Factors affecting students' acceptance of elearning environments in developing countries: A structural equation modelling approach. International Journal of Information and Education Technology, 3(1), 54-59.

Tarhini, A., Hone, K., and Liu, X. (2014). Measuring the moderating effect of gender and age on e-learning acceptance in England: A structural equation modeling approach for an extended technology acceptance model. Journal of Educational Computing Research, 51(2), 163-184.

Theriot, P. (2004). Student values and ethics in an e-learning environment. In D. Christopher \& S. Jaderstrom (Eds.), NBEA 2004 Yearbook, 42, 13-25.

Tirri, K., and Nevgi, A. (2000). Students' views on learning in virtual university. Finland. ERIC_NO: ED448121 
Journal of Social Sciences (COES\&RJ-JSS), 5(2), pp. 172-200

Upton, D. (2005). Online learning in nutrition dietetics: Student performance and attitudes. The Journal of Health Sciences and Practice, 3 (1), 56- 65.

Wiersma, W. (2000). Research methods in education: An introduction (7nd ed.). Boston: Allyn and Bacon.

Willis, T (2008). An evaluation of the Technology Acceptance Model as a means of understanding online social networking behaviour, Master thesis, University of South Florida.

Zamfiroiu, A., and Sbora, C. (2014). Statistical analysis of the behavior for mobile Elearning. Procedia Economics and Finance, 10, 237-243. 